\title{
Numerical Assessment of FPSO Platform Behaviour in Ship Collision
}

\section{Ozgur Ozguc}

Offshore platforms may potentially collide with vessels of various types, including visiting ships such as supply ships and passing ships. The most critical and relevant conditions, including the analysis and design approaches are introduced. Different ship types having different displacements and structural designs exert different vessel impact loads on impacted structures. This paper presents the findings of collision impact analyses of the side shell panel, bow and stern structures of Floating Production Storage Offloading (FPSO) platforms in case of impact, e.g. by a supply vessel or methanol tanker. As collision impact simulations continue to be conducted conservatively, the colliding positions of the striking vessel are presumed to be bow and stern only, with side force. In order to assess hull strength in collision events, non-linear FE simulations were performed by means of the MSC / DYTRAN tool, as these collision events result in more complex reactions. The degree of hull damage suffered by an FPSO vessel in different collision scenarios and at varying impact energy levels was determined in accordance with the NORSOK N-004 standard guidelines. Post-collision analyses were conducted to establish the structural integrity of the damaged hull after being exposed to environmental conditions for one year. The reduction of hull girder strength associated with the worst damage was

\section{KEY WORDS}

$\sim$ Collision accident

$\sim$ Offshore facilities

$\sim$ Non-linear finite element simulation

$\sim$ Energy absorption

$\sim$ Post-collision analysis

Department of Naval Architecture and Ocean Engineering, Istanbul Technical University, Istanbul, Turkey

e-mail: ozguco@itu.edu.tr

doi: 10.7225/toms.v09.n02.003

This work is licensed under (cc) BY evaluated and accounted for in the present study, providing no further damage occurs. Furthermore, the acceptance criteria for evaluation and corresponding consequences are calculated and discussed in detail. Finally, the findings from the present paper will help clarify the impact response of offshore structures and evaluation approaches and give valuable guidance for the design and operation of FPSO platforms.

\section{INTRODUCTION}

During operation, supply vessels are continuously servicing offshore production platforms and drilling rigs. Collisions between them are inevitable. Vessel impact with offshore facilities is one of the main issues to be considered in the design and evaluation of facility performance and safety, as a significant safety threat to ships and other offshore installations that can result in serious economic damage, environmental contamination and fatalities.

FPSO hull should be designed with due regard to potential loads caused by accidents such as collisions, dropped objects, fire, explosion and other abnormal events such as mooring line failures or broken risers. Structural improvements and/ or protective structures ensuring that the consequences of accidental loads do not compromise installation safety will be considered.

Collision is a major hazard to the safety of ships and other offshore installations and may result in severe economic loss, environmental pollution and fatalities. Ship collision accidents can be divided into approximately four categories, such as ship-ship, ship-offshore structure, ship-bridge and ship-iceberg collisions (ISSC, 2018).

You and Rhee (2016) conducted a study in an attempt to solve the intrinsic problem of critical collisions, inter alia considering the dilemma of slower ship's manoeuvrability, and the International Regulations for Preventing Collisions at Sea 
(COLREGs). They developed a collision ratio that can be used to determine the right moment to initiate collision avoidance manoeuvres.

Szlapczynski and Szlapczynska (2016) developed analytic formulas for domain-based collision risk parameters: degree of domain violation (DDV) and time to domain violation (TDV), to overcome the drawbacks of DCPA and TCPA, which lack efficient analytical solutions in real-time systems where computational time is essential. Zhang et al. (2016) proposed a novel method for detecting potential near-miss ship-ship collisions based on AIS data and discussed how near-miss data can be used to gain further insight into the safety of maritime transportation. Zhang et al. (2015) studied a multi-ship anti-collision decision support formula in distributed and real time. The formula was proven effective in helping avoid collisions when all ships act in accordance with COLREGs, as well as when some of them do not take action. Research on internal and external mechanisms gives us an understanding of responses in different ship collision scenarios.

Zhang et al. (2017) further analysed the validity and robustness of closed-form analytical methods they proposed in 1998 and further improved the accuracy of some parameters, obtaining 60 experimental results. A simple way of accounting for the effective mass of free surface liquids carried on board a ship was also introduced, and it was proved that the analytical procedure can be expanded to take into account the effect of ship roll on energy released by impact. By using nonlinear finite element code LSDYNA, Yu and Amdahl (2016a) first proposed a new coupled approach allowing the simultaneous calculation of structural damage and 6DOF ship motion during ship collision. The proposed method is particularly useful for design purposes as detailed knowledge of ship hull shape is not required. In addition, Yu et al. (2016b) upgraded the approach taking into consideration the hydrodynamic loads, based on linear potentialflow theory in the LS-DYNA code. The approach facilitates a fully coupled six degrees of freedom (6DOF) dynamic simulation of ship collision and grounding accidents, in contrast to previous studies that neglected ship motion and hydrodynamic loads.

Liu et al. (2015a and 2015b) proposed a simplified analytical method for examining energy absorption mechanisms of smallscale stiffened plate specimens, quasi-statically punched in the midspan by a hard indenter with a knife or a blunt edge. Both experiments and numerical simulations were carried out to validate the analytical method.

Calle et al. (2017) summarised a series of experiments including scaled collision tests of a T cross-section beam, frontal collision of an oil tanker with a rigid wall, ship grounding and collision between two oil tankers, to validate their finite element analysis. They indicated that the mechanical properties of materials, slight misalignments in test arrangements, failure criteria, weld joints and sloshing effect of ship cargo all influence differences between numerical and experimental results.

The public concern about ship collisions with offshore structures mainly focuses on the consequences. Since the costs of repair of offshore structures exceed the costs of repair of the striking ship, many researchers focus on improving the crashworthiness of offshore structures in accidental collision scenarios.

Zhang and Terndrup Pedersen (2015) conducted an analysis of collision energy and structural damage in ship offshore platform collisions in various scenarios. They considered ship collision with offshore installations one of the key concerns in the design and assessment of platform performances and safety. An example of an ice-strengthened supply vessel colliding with a jack-up rig was analysed and the crushing resistance of the colliding thin-walled structures evaluated.

Travanca and Hao (2015) analysed energy dissipation in high-energy ship-offshore jacket collisions, to gain a clearer understanding of the strain-energy dissipation phenomenon, particularly with respect to the ship-structure interaction. Vinnem et al. (2015) discussed the need for online decision support reduce the risk of FPSO-shuttle tanker collisions.

The characteristics of accidental loads and various methods of their calculation, theoretical and empirical formulae such as FEA (Finite Element Analysis) were well described in International Ship and Offshore Structures Congress (ISSC) reports. Collision and grounding accidents of ship structures are found in ISSC (2006).

The Association of Structural Improvement of Shipbuilding Industry of Japan conducted extensive collision and grounding tests (ISSC, 2003). One of the collision test models was a double side structure model made of mild steel. In the dynamics test, the bow model fell freely from the height of $4.8 \mathrm{~m}$ above the initial position of the outer hull, with the impact velocity of approx..9.7 $\mathrm{m} / \mathrm{sec}$. Ozguc et al., 2005 performed a LS-DYNA validation study using ISSC benchmark collision test. The force-penetration curve was calculated from the finite element simulation of the dynamics test and good correlation with the experimental result was achieved.

Storheim and Amdahl (2017) investigated the effect of various features of the complete stress-strain curve on anticipated outcomes of collision simulations. The effect of the assumed stress-strain curve was determined through nonlinear finite element analysis simulations of a full-scale impact scenario. The influence of strain-rate effects was investigated. The findings revealed that the slope of the stress-strain curve determines strain localisation, and thereby when and where the fracture propagates. The slope was strongly dependent on the yield ratio, yield plateau and the fracture elongation, parameters having significant statistical variation within a material grade. 
Depending on the size and speed of the impacting ship, anything from damage to hull rupture, oil pollution, flooding, and loss of buoyancy, capsizing, and sinking may occur. As supply vessels and tankers frequently visit FPSOs to transport consumables and chemicals, there is a risk of collision between two structures. Hence, during structural design, special attention needs to be paid to the minimization of damage from such accidents (Ozguc, 2018).

The main concern regarding vessel impacts with offshore platforms are the consequences. Since the costs of repair and maintenance of offshore facilities are higher than those of the striking vessel, several studies focused on the method of improving the crashworthiness of offshore structures in unintentional collision scenarios. In addition, as the number of offshore wind turbines along the coastlines increases, collisions between trading vessels and offshore wind turbines become more common (ISSC, 2018).

The outcome of a vessel-platform collision depends on the kinetic energy, carrying weight and speed of the ship, as well as on the deformation capacity of both the structure and the vessel. When two bodies collide, the rigidity of their deformation can result in different outcomes, such as a near-elastic collision (where both bodies travel in opposite directions after collision), a perfectly inelastic collision (both bodies travel together) or an in-between situation. NORSOK N-004 codes include three separate design scenarios, such as the strength design, where energy is dissipated by vessel, the ductile design, where energy is dissipated by the structure, and the halfway compromised shared-energy design, which is very difficult to measure.

The purpose of the research was to carry out a sensitive numerical study of offshore unit actions in case of impact by a hard and soft 5000 ton vessel, moving at the speeds of $0.5 \mathrm{~m} / \mathrm{s}$ and $2 \mathrm{~m} / \mathrm{s}$ as specified in the Standards. ABAQUS finite element tool was employed to assess the deformation and dissipation of energy in both vessel and platform structure during local collision (Rigueiro et al. 2017).

FPSOs take on oil and gas through the riser system, process it and store it in vessel tanks which are kept in place by a mooring or a dynamic positioning system as defined by Moan et al. (2003). In accordance with the HSE (2000) study, during operation they may be struck by a) supply vessels approaching or leaving the installation, b) tankers while refuelling, c) ships and fishing vessels passing by the installation, and d) floating installations, such as flotels. A part of collision energy may be dissipated as strain energy in both FPSO and the striking vessel, likely contributing to a significant amount of plastic tension.

Zhang et al. (2015) conducted a research using a numerical simulation method to analyse crashworthiness of Floating Liquefied Natural Gas (FLNG) side structures during side by side offloading process in case of collision. Two typical collision scenarios have been described, based on the parameters obtained from the model test. Instead, the LS-DYNA code simulated collision scenarios. A special limit collision condition was suggested based on the structural response of LNG CCS (cargo containment system). The structural response of the CCS was given considerable attention to determine the level of protection of FLNG side structures.

Ning et al. (2013) developed numerical methods to assess the structural integrity of a generic Spar hull in collision with a large supply ship and explain the progressive nature of collision damage suffered. The analysis of dynamic and nonlinear finite elements was carried out for two collision scenarios using ABAQUS / Explicit tool, respectively. One was a practical simulation where kinetic energy of the impact dependent upon initial impact velocity and ship's total mass during collision was slowly depleted. The other was a simpler theoretical approach where a ship bow's impact velocity was constant during the collision, or the total impact energy was infinite. Progressive impact damage to hull structures was correctly recorded for purposes of structural integrity evaluation, using a combination of optimized progressive material damage models and Mises plasticity, which is a part of the plasticity theory best suited to ductile materials, such as some metals. Prior to yield, material response can be assumed to be nonlinear elastic, viscoelastic, or linear elastic.

Zhang et al. (2015) gave an overview of colliding energy and structural damage in vessel - offshore structure collisions in various collision scenarios. The facility was either viewed as rigid or flexible, and its response to collision energy and structural damage was examined. An example of a collision of an icestrengthened supply ship with a jack-up structure, and crushing resistance of the thin-walled structures involved was explored.

Wang and Pedersen (2007) reviewed the work and analyses relating to ship-FPSO collision risk assessment. The emphasis was on current requirements, FPSO collision occurrence, FPSO collision design scenarios, collision dynamics, impacts and acceptance requirements. There have been some developments in the study of ship collision and grounding since the 1990s. Issues unique to vessel-FPSO collisions meriting further attention have been addressed.

Amdahl et al. (2012) investigated large vessel-vessel collisions with jacket legs, with specific focus on NORSOK $\mathrm{N}-004$ recommended analysis procedure. A jacket leg and the shipside of a typical supply vessel were modelled, and LS-DYNA software ran impact simulations. The denting resistance of the jacket leg and shipside indentation resistance were compared with NORSOK guidelines. The distribution of energy dissipation and ship and leg damage were analysed for legs of different thicknesses and two contact positions. 
Yu and Amdahl (2018) reviewed state-of-the-art response dynamics and mechanics of offshore tubular structures subject to mass impacts, including material modelling, ship impact loading, ship and platform energy absorption, global and local response of tubular structures, residual strengths of damaged tubular members, and design considerations to mitigate impacts. Literature provided a wealth of material, with priority given to recent discoveries and broadly influential classical sources. The findings were compared and discussed. Potential directions of study that would improve our understanding of impact dynamics and accurate and effective design equations have been proposed.

Mujeeb-Ahmed et al. (2018) used an automatic identification system (AIS) database to conduct a probabilistic collision-risk analysis for offshore platforms exposed to controlled collisions with passing ships. The study first defined the statistical distribution of vessel traffic analysed, and then discussed how these findings could be effectively used to predict collision frequency and impact energy for different vessel categories, based on a simple probabilistic approach. Frequency calculations took into account the effects of different collision avoidance measures such as improved collision warning systems, and the ability of platforms to rotate using thrusters. This risk approach could be applied to both new and existing platforms in the design and development stage.

Amante and Estefen (2018) published an accident analysis that included accidents between ships and offshore platforms. The study documented few existing publications that addressed this issue in Brazilian waters and presented the effects of 11 years of collecting collision data on Petrobras platforms.

Pedersen (2015) outlined some of the available analytical elements for collision frequency and response estimates for different types of offshore installations and explained how these methods could be used to identify appropriate risk management options.

Moan (2019) focused on design to improve robustness or damage tolerance and ensure structural integrity during service life. A simple definition of robustness is that it is "the ability of a structure to limit the escalation of accident scenarios into accidental conditions with a magnitude disproportionate to the original cause." Robustness requirements apply to different failure modes that can ultimately result in fatalities, pollution or property loss. Structures supported on the seafloor can experience structural, foundation or soil failures, while buoyant structures can capsize, sink, or suffer hull or mooring system failure.

Ozguc (2019) focused on the general approach and design of FPSO accident scenarios, using advanced methods such as nonlinear finite element method used to provide structural responses during and after impact. As varying collision scenarios and impact energy levels were simulated, the degree of FPSO hull damage was assessed using the criteria defined in the NORSOK standard. The accident case of 5 years on-site setting accounted for the Accidental Limit State (ALS). Different collision scenarios were described as supply ship collision bow on, supply ship collision side on, supply ship collision stern on, and tanker collision bow on off. Conservatively, the impacting vessel was deemed not to deform during collision. Damage to FPSO hull, including flare tower foundations, aft muster station, offloading reel and piping, and safety of green water above cargo deck, was assessed.

This paper incorporates the findings of impact analyses of collision of a striking ship, e.g. supply ship and methanol oil tanker, with FPSO side hull, bow and stern structures. Collision impact analyses were performed conservatively and the presumed collision path of the struck vessel was only bow and stern with side energy. Non-linear FE analyses were performed using the MSC/DYTRAN code to test the strength of the hull structure in case of collision events, as collision accidents require more complex responses. The extent of FPSO hull damage in various collision scenarios and at different impact energy levels was computed in keeping with the guidelines from the NORSOK code. The reduction of a ship's longitudinal strength after collision damage was also calculated. The residual strength of damaged structures must be kept at a certain level to avoid potentially catastrophic consequences.

\section{FPSO VESSEL DESIGN}

Single bottom and double side hull was designed as shown in Figure1, with topsides weighing 32,300 tons. The FPSO is moored in a fixed position and the suction piles and ground chain are linked. FPSO facilities have been designed for a 20year service life. FPSO's topside control system was designed to accommodate 21 wells and a fourth subsea separation unit. Subsea production lines, injection lines and risers for spread moored FPSO.

FPSO characteristics are as follows;

- $\quad$ Overall length (L): 325.05 m

- $\quad$ Length between perpendiculars $\left(\mathrm{L}_{b p}\right): 325.00 \mathrm{~m}$

- $\quad$ Breadth (B): $61.00 \mathrm{~m}$

- $\quad$ Depth (D): $32.00 \mathrm{~m}$

- Design draft $\left(\mathrm{T}_{\mathrm{d}}\right): 24.56 \mathrm{~m}$

- $\quad$ Scantling draft $\left(T_{s}\right): 25.55 \mathrm{~m}$

- Block coefficient for scantling $\left(C_{b}\right): 0.983$ 

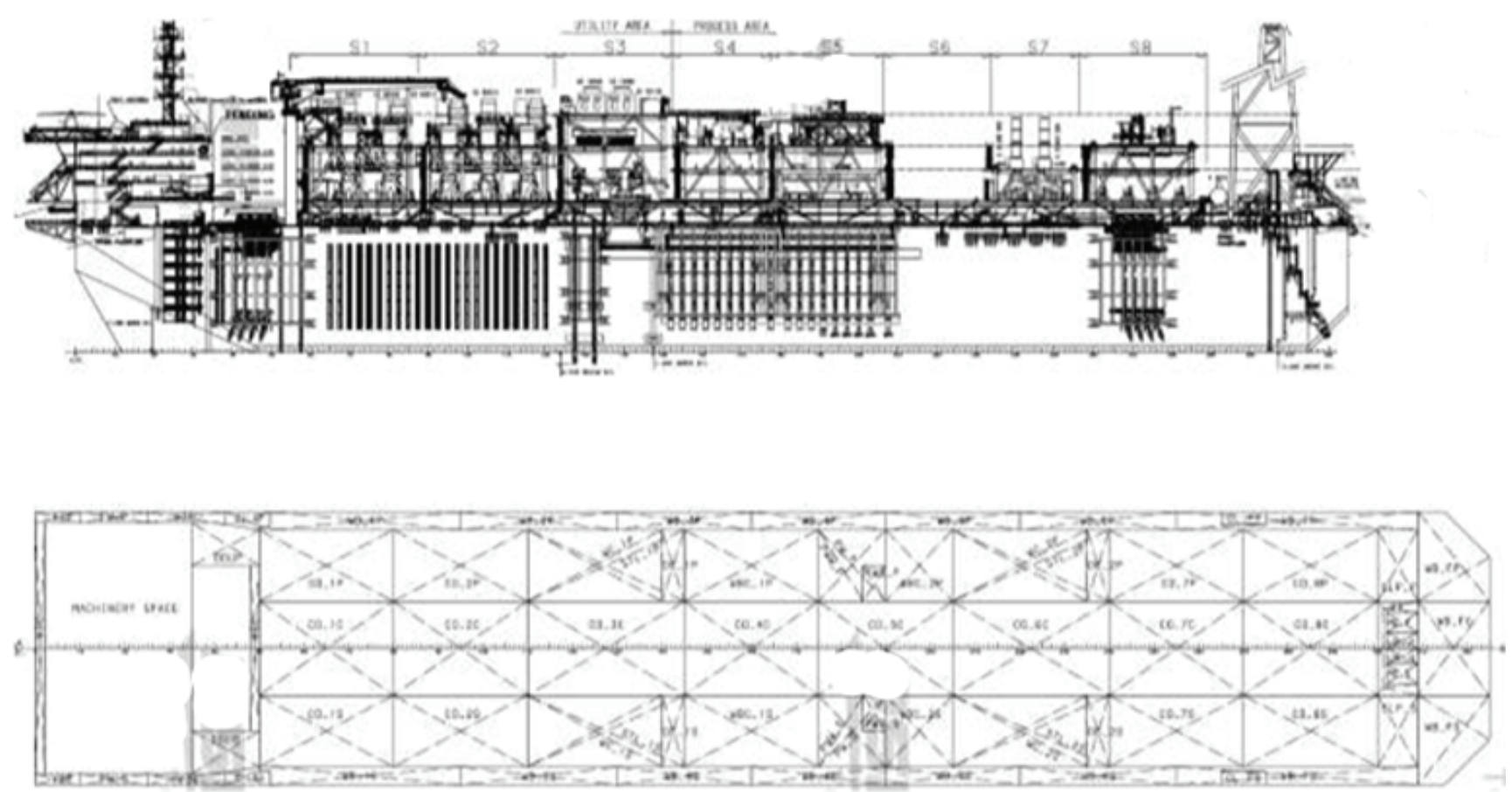

Figure 1.

General layout of a FPSO vessel.

\section{COLLISION IMPACT ANALYSIS SCENARIOS}

Ship collision analysis is often conducted in displacement controlled manner, i.e. the analysis of external motion dynamics is separate from the evaluation of structural consequences. Such analysis assumes a certain prescribed penetration path. This assumption was found to be valid in case of symmetric right angle collisions, while in non-symmetric collisions penetration depth depends on the structural configuration and mass of the ship, collision location, etc. Differences in damage description and penetration depth can be significant.

Brown (2002) compared the coupled SIMCOL model with the decoupled model of Pedersen and Zhang (1998) and concluded that, while total energy was similar in both approaches, the decomposition of the total energy into transverse and longitudinal energy was significantly different. Tabri and Broekhuijsen (2011) came to the same conclusion in their coupled and decoupled finite element simulation. They found that decoupled simulation could give an erroneous description of penetration depth in oblique angle collisions. With respect to ship collisions, prescriptive scenarios exist for ship-platform or ship-FPSO collisions; see for example recent guidelines by LR (2014).

In offshore ship collision studies conducted in the design stage, the speed of the striking vessel must not to be less than
$2.0 \mathrm{~m} / \mathrm{s}$ and the most probable impact location should be determined by risk analysis, taking into account factors that affect the exact location, such as tidal changes and vessel motion due to conditions at sea (NORSOK-N-003, 2007). In the absence of specific impact zone information, values between $10 \mathrm{~m}$ below LAT and $13 \mathrm{~m}$ above HAT ((NORSOK-N-003, 2007) are to be considered. Force-indentation, energy-deformation and forcedeformation curves are available in DNV-RP-C204 (2010) for different ship sizes and impact locations (bow, stern, broad side). Should a more detailed investigation be required than provided in the guidelines defined in classification rules, a local explicit FE analysis should be considered, with emphasis on material properties and failure criteria.

Impact energies for collision analyses are provided in Table 1. Collision locations used in the analyses are shown in Figure 2. Only one draft for each hull plating and the collision angle of 90 degrees between striking vessel and FPSO (that is, perpendicular to FPSO) are taken into account in hull plating evaluation, as this is where the most severe damage could occur. Especially for operational collisions with the side shell structure, in real life simulations the collision direction of the supply ship is not bow but stern. Hull plating locations considered in collision impact analyses are shown in Figures 3-5. The main dimensions of typical supply ship and methanol tanker are summarized in Table 2 and Table 3. 
Table 1.

Ship collision scenarios for nonlinear FE analyses.

\begin{tabular}{|c|c|c|c|c|c|c|c|}
\hline $\begin{array}{l}\text { Collision } \\
\text { location }\end{array}$ & Loading & Acceptance criteria & $\begin{array}{l}\text { Collision } \\
\text { direction }\end{array}$ & Speed & $\begin{array}{l}\text { Colliding } \\
\text { vessel }\end{array}$ & $\begin{array}{l}\text { Displace } \\
\text { ment }\end{array}$ & $\begin{array}{l}\text { Impact } \\
\text { energy }\end{array}$ \\
\hline \multirow{5}{*}{ Side shell } & \multirow{2}{*}{ Operational } & \multirow{2}{*}{$\begin{array}{l}\text { Energy absorbed by elastic } \\
\text { deformation }\end{array}$} & Bow & \multirow{2}{*}{$0.64 \mathrm{~m} / \mathrm{s}$} & \multirow{5}{*}{ Supply ship } & \multirow{5}{*}{$7,500 \mathrm{t}$} & $1.7 \mathrm{MJ}$ \\
\hline & & & Side & & & & $2.2 \mathrm{MJ}$ \\
\hline & \multirow{2}{*}{ Accidental } & \multirow{2}{*}{$\begin{array}{l}\text { Energy absorbed by plastic } \\
\text { deformation (no breach) }\end{array}$} & Bow & \multirow{2}{*}{$1.7 \mathrm{~m} / \mathrm{s}$} & & & $11.9 \mathrm{MJ}$ \\
\hline & & & Side & & & & $15.2 \mathrm{MJ}$ \\
\hline & Critical & $\begin{array}{l}\text { Breach of shell up to contact } \\
\text { with inner hull }\end{array}$ & Bow & $3.48 \mathrm{~m} / \mathrm{s}$ & & & $50 \mathrm{MJ}$ \\
\hline \multirow{3}{*}{$\begin{array}{l}\text { Bow } \\
\text { (Tandem end) }\end{array}$} & \multirow{2}{*}{ Accidental } & \multirow{2}{*}{$\begin{array}{l}\text { Energy absorbed by plastic } \\
\text { deformation (no breach) }\end{array}$} & Bow & \multirow{2}{*}{$1.7 \mathrm{~m} / \mathrm{s}$} & \multirow{3}{*}{$\begin{array}{l}\text { Methanol } \\
\text { tanker }\end{array}$} & \multirow{3}{*}{$10,000 t$} & $16 \mathrm{MJ}$ \\
\hline & & & Side & & & & $20.5 \mathrm{MJ}$ \\
\hline & Critical & $\begin{array}{l}\text { Breach of shell up to contact } \\
\text { with inner hull }\end{array}$ & Bow & $4.35 \mathrm{~m} / \mathrm{s}$ & & & $104 \mathrm{MJ}$ \\
\hline \multirow{3}{*}{ Stern } & \multirow{2}{*}{ Accidental } & \multirow{2}{*}{$\begin{array}{l}\text { Energy absorbed by plastic } \\
\text { deformation (no breach) }\end{array}$} & Bow & \multirow{2}{*}{$1.7 \mathrm{~m} / \mathrm{s}$} & \multirow{3}{*}{ Supply ship } & \multirow{3}{*}{$7,500 t$} & $11.9 \mathrm{MJ}$ \\
\hline & & & Side & & & & $15.2 \mathrm{MJ}$ \\
\hline & Critical & $\begin{array}{l}\text { Breach of shell up to contact } \\
\text { with inner hull }\end{array}$ & Bow & $3.48 \mathrm{~m} / \mathrm{s}$ & & & $50 \mathrm{MJ}$ \\
\hline
\end{tabular}

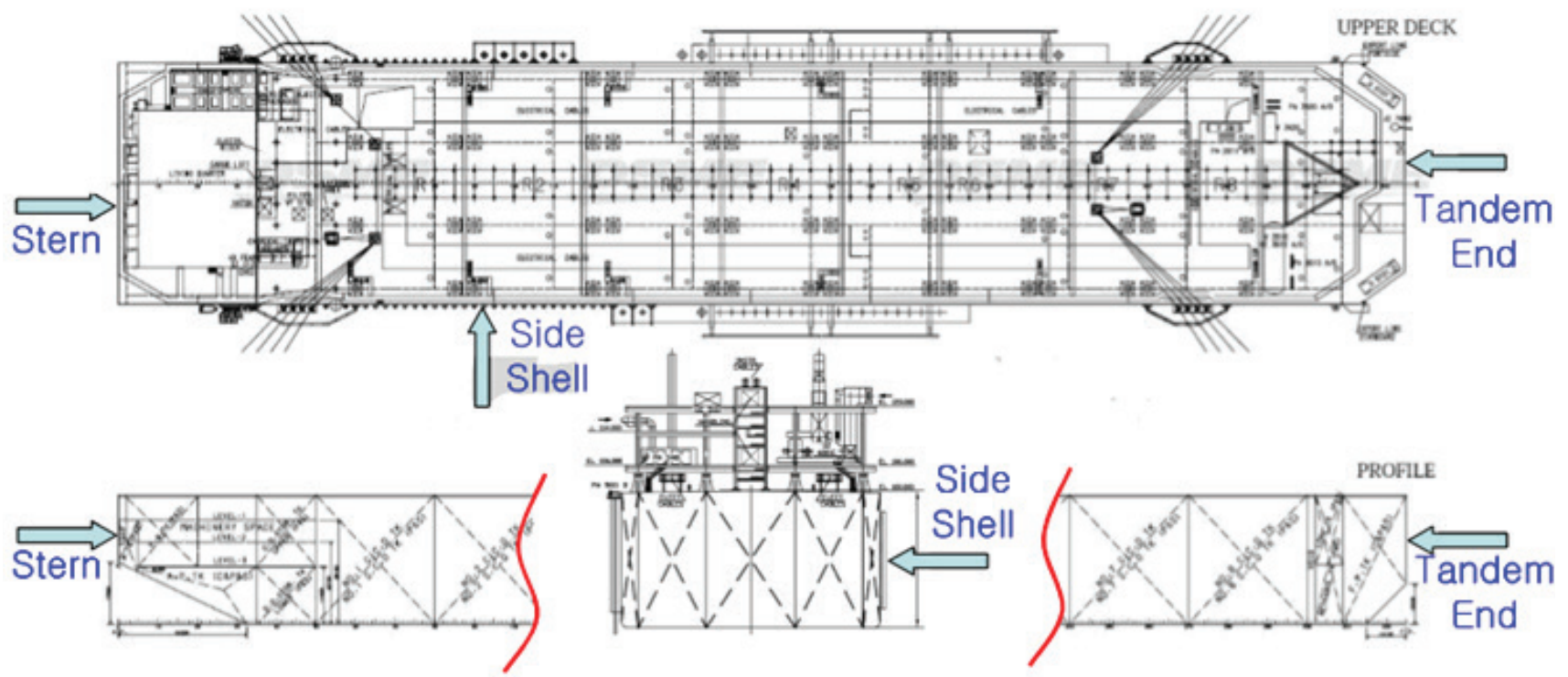

Figure 2.

Colliding position and collision direction for collision analyses. 


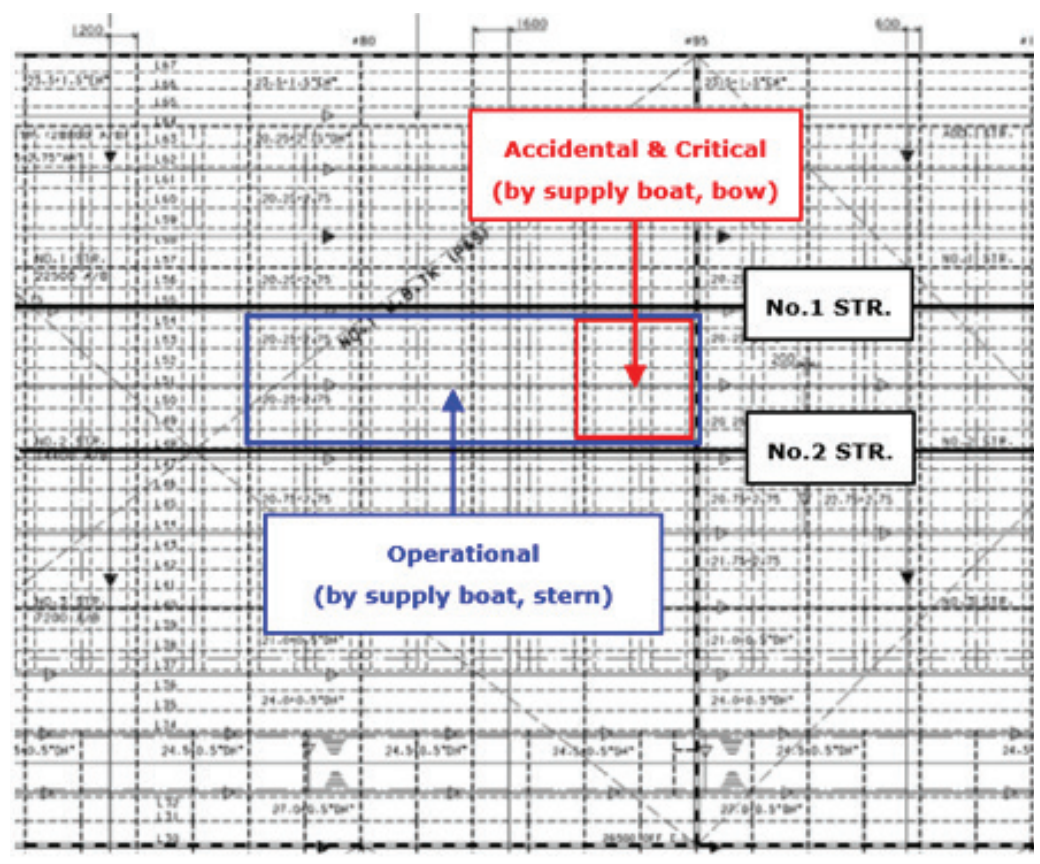

Figure 3.

Vertical striking position on FPSO side shell for collision analyses.

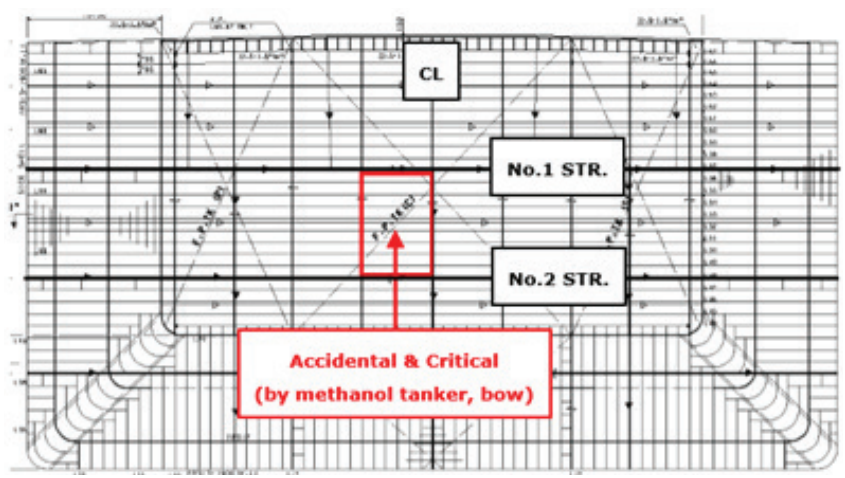

Figure 4.

Vertical striking position on FPSO bow for collision analyses.

Impact velocities are calculated as in Eq.1.

$E=0.5\left(M+A_{d}\right) V^{2}$

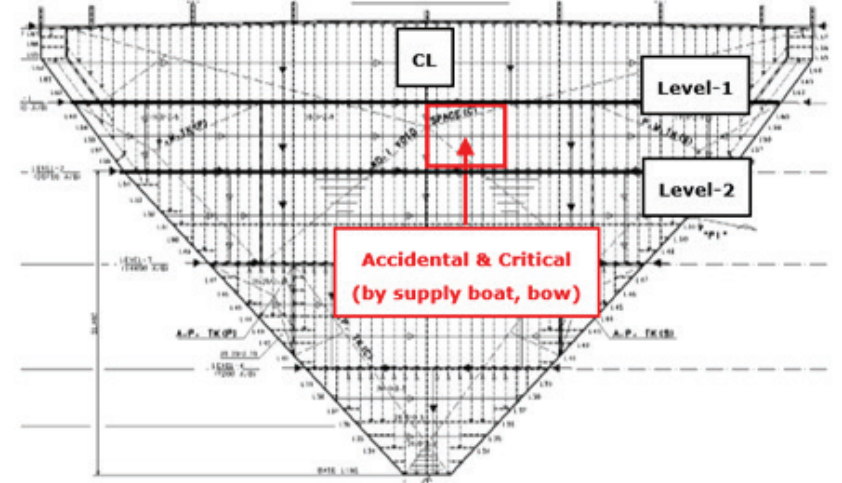

Figure 5.

Vertical striking position on FPSO stern for collision analyses.t

Acceptance criteria allow severe plastic deformation of hull plating, providing there is no oil leakage and the integrity of vessel hull strength is not compromised.

$M=$ striking ship displacement $(\mathrm{t})$

$A_{d}=$ added mass ( $\left.\mathrm{t}\right)$

$V=$ collision speed $(\mathrm{m} / \mathrm{s})$ 
Table 2.

Main dimensions of typical supply ship.

\begin{tabular}{ll} 
Overall length & $90.00 \mathrm{~m}$ \\
\hline Overall beam & $19.00 \mathrm{~m}$ \\
\hline Depth & $8.00 \mathrm{~m}$ \\
\hline Draught & $6.50 \mathrm{~m}$ \\
\hline Max. dead weight & $3,800 \mathrm{t}$ \\
\hline Light displacement & $3,700 \mathrm{t}$ \\
\hline Loaded displacement & $7,500 \mathrm{t}$ \\
\hline Cruise speed & 12 knots \\
\hline Max. speed & 16 knots \\
\hline
\end{tabular}

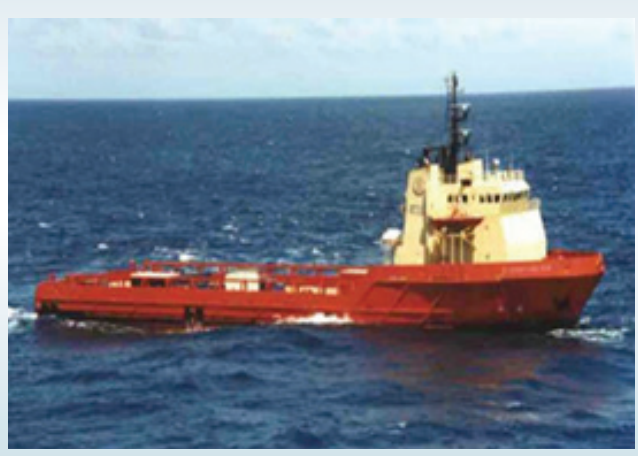

Table 3.

Main dimensions of typical methanol tanker.

\begin{tabular}{ll} 
Overall length & $126.95 \mathrm{~m}$ \\
\hline Length perpendicular & $121.40 \mathrm{~m}$ \\
\hline Overall beam & $19.60 \mathrm{~m}$ \\
\hline Moulded depth & $9.35 \mathrm{~m}$ \\
\hline Draught & $6.80 \mathrm{~m}$ \\
\hline Deadweight at design & $10,000 \mathrm{t}$ \\
\hline Tonnage & $6,688 \mathrm{GT}$ \\
\hline Max. speed & $13.5 \mathrm{knots}$
\end{tabular}

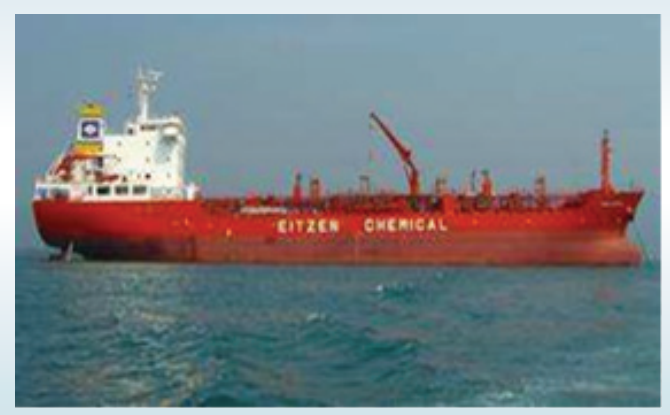

\section{BOW HULL PLATING}

Impact on bow hull plating is assumed to be caused by a 10,000t methanol tanker.

The accidental impact of methanol tanker at the speed of $1.7 \mathrm{~m} / \mathrm{s}$ generates kinetic energy of $16 \mathrm{MJ}$ in a bow/stern impact and $20.5 \mathrm{MJ}$ in a side-on impact with added mass factors. The hull plating may suffer significant plastic deformations but no leak is accepted.

Collision impact analysis of critical case on tandem end hull plating is carried out for verification purposes. Calculated ship impact speed is $4.35 \mathrm{~m} / \mathrm{s}$, required to generate the kinetic energy of 104 MJ. The maintenance of inner collision bulkhead structure integrity in case of breached outer shell structure is examined at impact locations.

The striking vessel is presumed to be a hard body, which assumption is considered to produce conservative results with respect to safety. Additionally, the FPSO vessel is presumed to stay in its position during collision events.

\section{RUPTURE STRAIN AND MATERIAL PROPERTY}

The amount of kinetic energy absorbed as strain energy must be calculated in accordance with the NORSOK standard. However, all kinetic energy is assumed to be consumed in a conservative way to strain water. The percentage of rupture strain is also determined depending on the grade of steel as shown in Table 4 below, in accordance with the NORSOK standard. The percentage of rupture strain for the grade of steel that is not specified in the table is calculated in the interpolation. In addition, material properties used in impact analysis are indicated in Table 5.

Table 4.

Suggested $\varepsilon_{\mathrm{cr}}$ values for various steel grades under NORSOK.

\begin{tabular}{ll} 
Steel grade & Critical strain $\left(\boldsymbol{\varepsilon}_{\mathrm{cr}}\right)$ \\
\hline Mild & $20 \%$ \\
\hline HT 32 & $16.7 \%$ \\
\hline HT 36 & $15 \%$ \\
\hline
\end{tabular}


Table 5.

Material properties to be used in nonlinear finite element simulations (DNVGL-RP-C208).

\begin{tabular}{llll} 
Steel grade & Mild & HT-32 & HT-36 \\
\hline Yield stress & $235 \mathrm{MPa}$ & $315 \mathrm{MPa}$ & $355 \mathrm{MPa}$ \\
\hline Elastic strain & $0.20 \%$ & $0.20 \%$ & $0.20 \%$ \\
\hline Ultimate tensile stress & $450 \mathrm{MPa}$ & $530 \mathrm{MPa}$ & $560 \mathrm{MPa}$ \\
\hline Critical failure strain & $20.0 \%$ & $16.7 \%$ & $15.0 \%$ \\
\hline Density & $7850 \mathrm{~kg} / \mathrm{m} 3$ & $7850 \mathrm{~kg} / \mathrm{m} 3$ & $7850 \mathrm{~kg} / \mathrm{m} 3$ \\
\hline Young's modulus & $2.06 \mathrm{e}+11 \mathrm{~N} / \mathrm{m} 2$ & $2.06 \mathrm{e}+11 \mathrm{~N} / \mathrm{m} 2$ & $2.06 \mathrm{e}+11 \mathrm{~N} / \mathrm{m} 2$ \\
\hline Poison's ratio & 0.3 & 0.3 & 0.3 \\
\hline Tangent modulus & $1085 \mathrm{MPa}$ & $1303 \mathrm{MPa}$ & $1385 \mathrm{MPa}$ \\
\hline Hardening parameter & 1.0 & 1.0 & 1.0 \\
\hline Strain rate $(\mathrm{C})$ & 40.4 & 3200 & 3200 \\
\hline Strain rate $(\mathrm{P})$ & 5.0 & 5.0 & 5.0
\end{tabular}

\section{ASSESSMENT METHOD}

In this study, FE analyses focus on a multitude of potential ship collision scenarios and structural configurations to be analysed. FE analysis is the most flexible method that can be used to account for possible effects and evaluate the relevant factors such as impact energy, boundary conditions, material, discrete indenter shape, rigidity and indentation location. Assessing non-linear material behaviour is essential for determining the response of a structure. The properties of elastic-plastic materials should be described by application;

- $\quad$ initial yield criterion;

- hardening rule where yield condition is modified due to the history of plastic flow;

- flow rule that updates plastic rigidity using an incremental stress-strain relationship.

The explicit method of FE analysis has the following characteristics:

- capability to manage very low dynamic response times, allowing highly discontinuous processes for large models;

- tolerance to large deformations and rotations;

- capability to analyse assembled parts with very general contact definitions;

- allows for the use of linear geometrical deformation theory if small deformations and rotations are presumed;

- allows for the use of adiabatic stress analysis if heat generation is assumed to be associated with inelastic dissipation; - $\quad$ permits the quasi-static analysis of models with complex contact definitions;
- $\quad$ permits the deletion of the element to the rupture model.

Explicit nonlinear FE simulations were carried out to examine the strength of structures against collision impact, including the large deformation of structures and the properties of elasto-plastic material. In non-linear FE analysis, the strain hardening effect together with ultimate stress are presented as a bi-linear strain-stress curve based on material grades as depicted in Figure 6 and Figure 7. Fracture was determined on the basis of the critical plastic strain of material utilized in accordance with the NORSOK N-004 standard. Figure 8 shows the properties of the material employed in the nonlinear simulation. Ultimate stress data are average values and critical strain data are in accordance with the NORSOK N-004 standard. The Cowper-Symonds rate enhancement formula is employed to account for the effect of strain rate on material properties as provided by (2), (3) and (4) presented in Figure 6 and Figure 7.

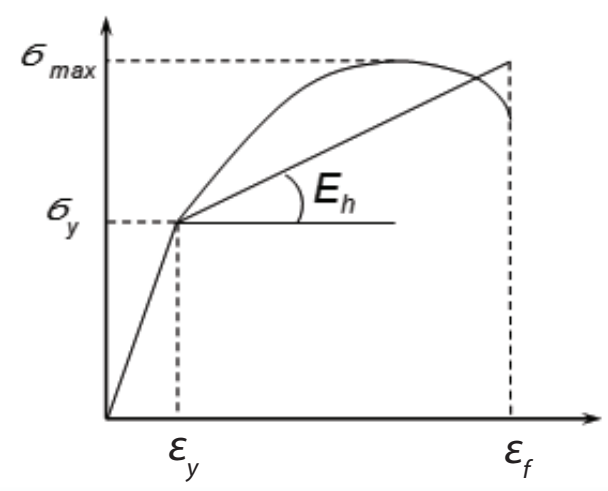

Figure 6.

Stress-strain curve for bilinear material. 
$\sigma_{p}=\sigma_{y}+\frac{E E_{h}}{E-E_{h}} \varepsilon_{p}$

$E_{h}=\frac{\sigma_{y \max }-\sigma_{y}}{\varepsilon_{f}-\varepsilon_{y}}$

$\sigma_{y}=$ Yield stress

$E_{h}=$ Hardening modulus

$\sigma_{p^{\prime}} \varepsilon_{p}=$ Plastic stress and Plastic strain

$E=$ Young's modulus

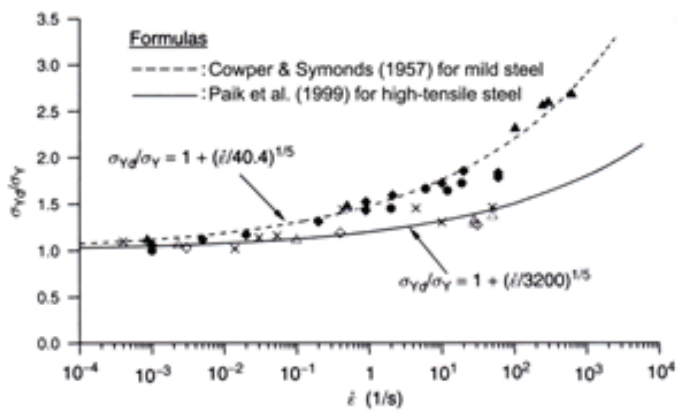

Figure 7.

Strain rate effect.

$\frac{\sigma_{y d}}{\sigma_{y}}=1+\left\{\frac{\varepsilon}{D}\right\}^{1 / q}$

$\begin{array}{lll}\text { Mild steel: } & D=40.4, & q=5 \\ \text { HT steel } & D=3200, & q=5\end{array}$

$\sigma_{y d}$ is dynamic yield stress; $\sigma_{y}$ is static yield stress. The material properties of the initial configuration are in accordance with the steel quality used for the FPSO vessel, i.e. steel grades Mild, HT32 and HT36 as per DNVGL-RP-C208 (2019).

Collision simulation, including material and geometric nonlinearities, was performed using MSC/DYTRAN tool. To determine the strength capacity of supply ship and oil carrier hull plating in collision events, advanced nonlinear FE simulation was performed, as collision events cause complex responses. The properties of elements used in the FE models were obtained by deducting the DNVGL rule corrosion addition from the rule gross scantling in accordance with DNVGL Class.

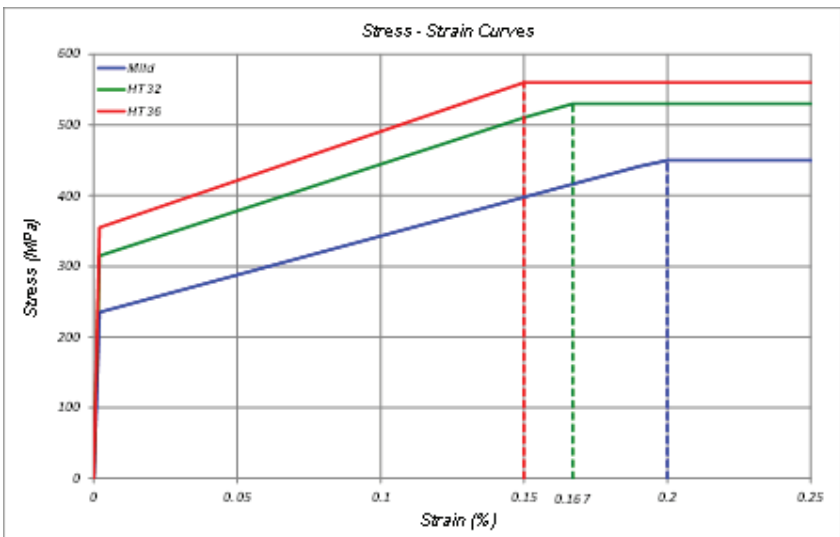

Figure 8.

Stress-strain curves for different steel grades.

\section{FINITE ELEMENT MODEL}

MSC/PATRAN was used to generate the FE models. The FE models were generated by using only shell elements, and the areas concerned were modelled using a mesh scale of about 100 $\mathrm{mm} \times 100 \mathrm{~mm}$. Taking the DNVGL rule into account, the corrosion effects were reflected. The striking ships were presumed to be infinitely rigid and FPSO's hull structure was thus presumed to absorb all energy. However, their rigidity should be taken with caution as energy dissipation in the bow is not taken into consideration. Figures 9 and 19 show FE models of FPSO hull structure with striking rigid ship in case of side collision, and FE model in case of bow and stern collision.

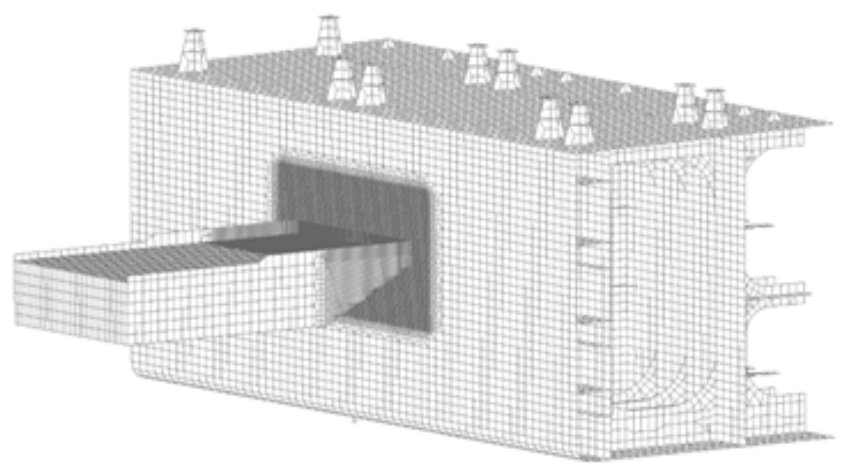

Figure 9.

FE model for impact analysis of side shell collisions operational event. 


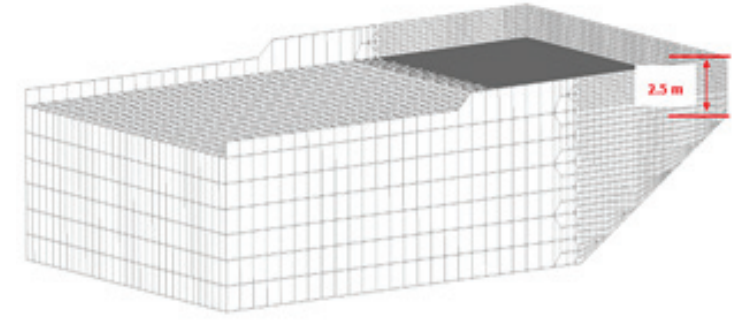

Figure 10.

FE model of supply ship (stern).

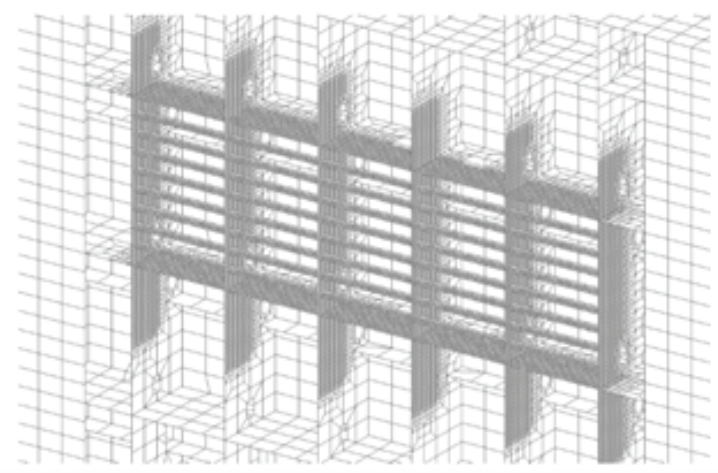

Figure 11.

FE model of side shell structure.

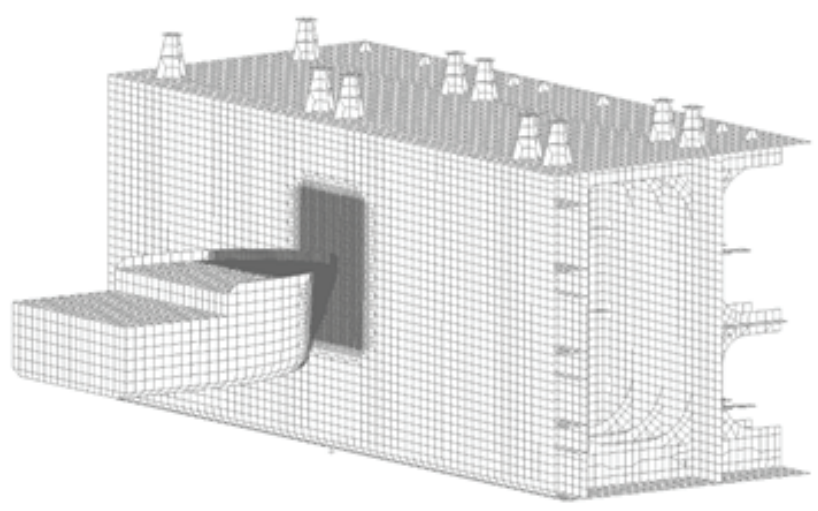

Figure 11.

FE model for side shell collision impact analysis -accidental / critical events.

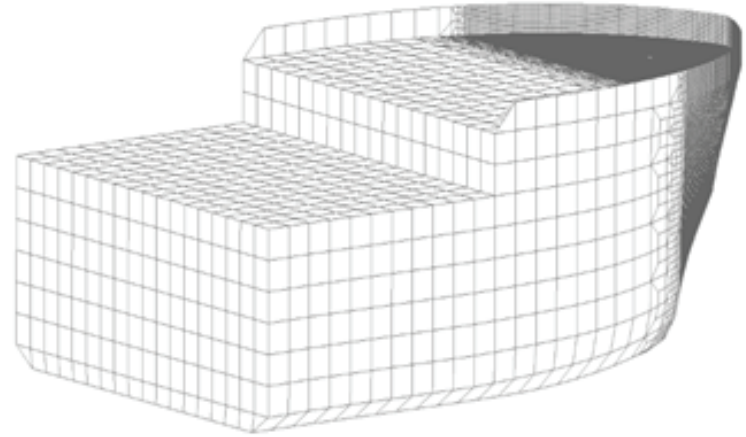

Figure 13.

FE model of supply ship (bow).

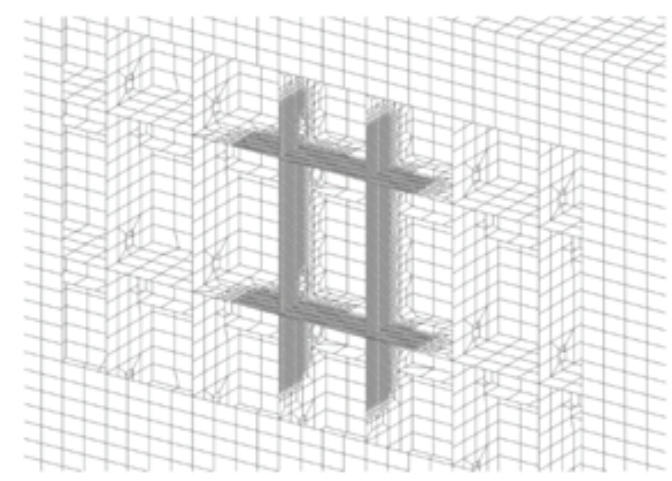

Figure 14.

FE model of side shell structure.

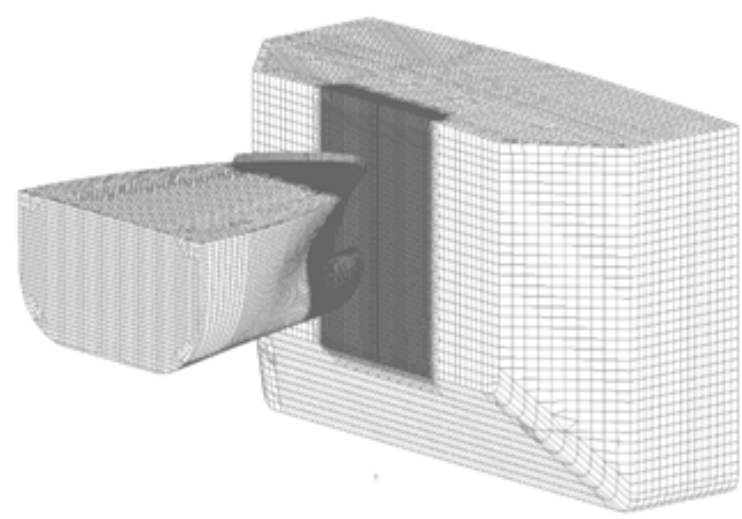

Figure 15.

FE model for impact analysis of bow collisions. 


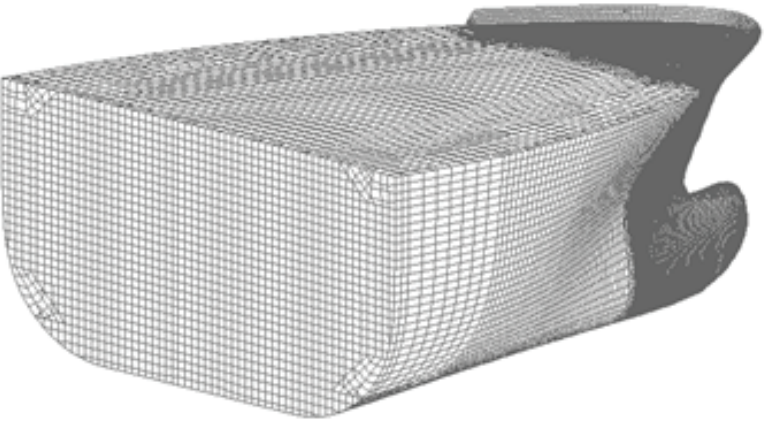

Figure 16.

FE model of methanol tanker (bow).

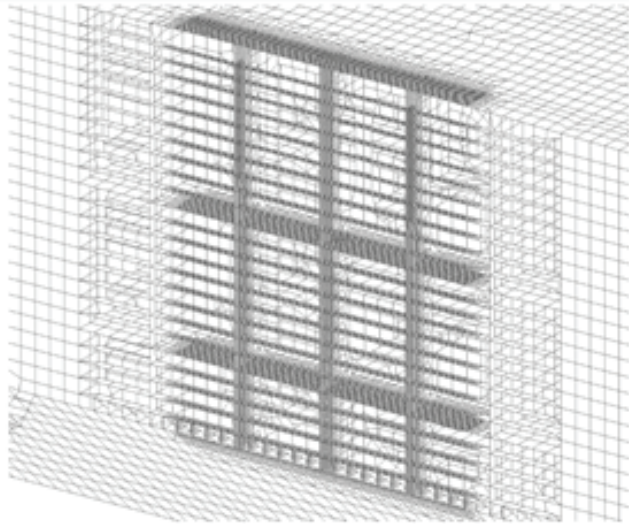

Figure 17

FE model of bow structure.

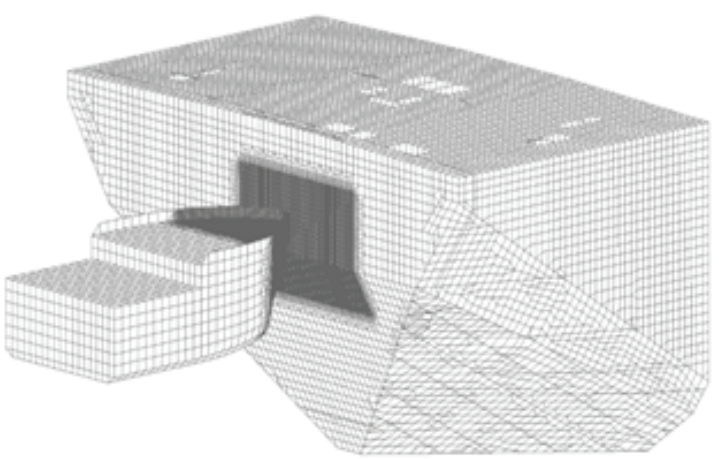

Figure 18.

FE model for stern collision impact analysis.

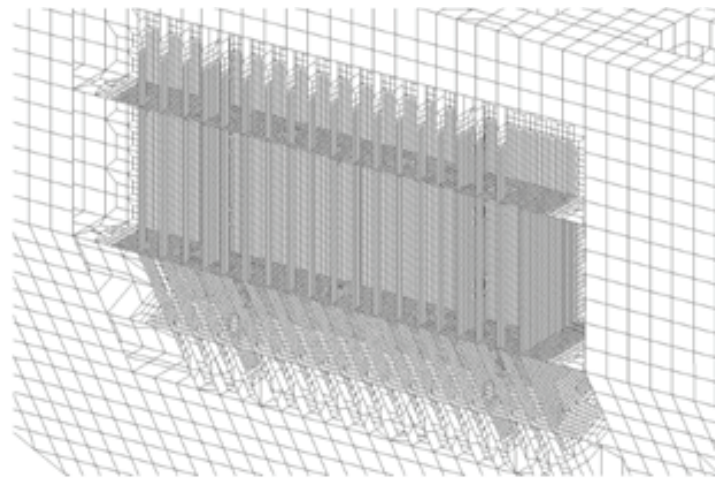

Figure 19.

FE model of stern structure.

\section{APPLIED BOUNDARY CONDITIONS}

The struck vessel is presumed to remain in place during impact. The assumption gives conservative results in terms of safety. Hence, boundary condition of FPSO hull structure has been implemented as fully fixed. Figure 20 depicts FE model with boundary plots for the side shell collision analysis.

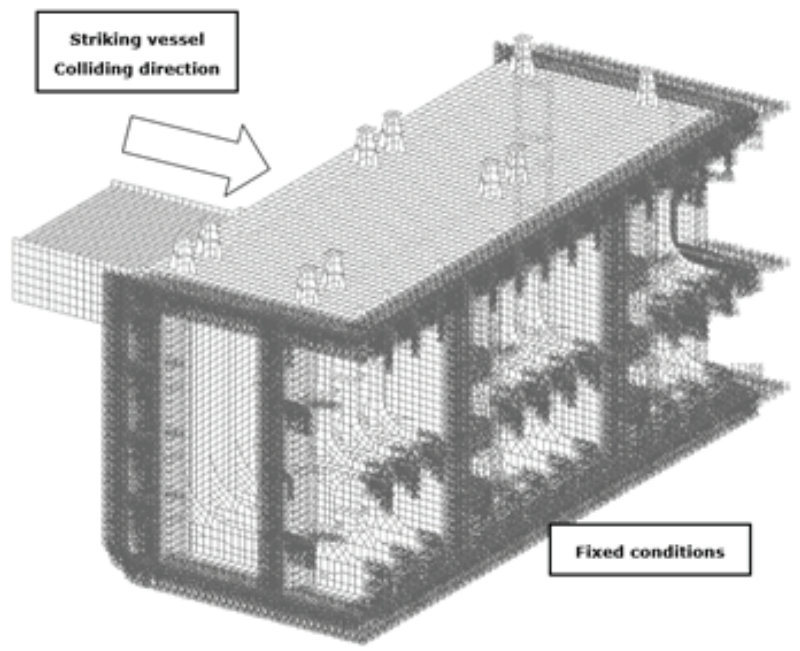

Figure 20.

Boundary conditions for FPSO (fixed).

\section{FINITE ELEMENT ANALYSIS}

Collision events were simulated by assigning the rigid body various initial speeds to represent a colliding ship, such as a supply vessel or a methanol oil tanker. The mass of the rigid body varies depending on collision direction with the corresponding added mass coefficients. 
The surface contact between the impacting ship and the FPSO hull structure during collision was calculated. During the impact phenomenon, an infinite friction coefficient was employed, as it is known for preventing slipping at the contact point in the conservative method. In the MSC/DYTRAN tool, surface to surface contact was established. Self-contact due to great FPSO vessel hull deformation was frequent.

\section{THE RESULTS OF FINITE ELEMENT ANALYSIS}

In all impact load cases, nonlinear FE analyses have been performed to validate and check structural capacity in ship collision events.

- Deformed shape plots and plastic strain contour,

- Deformed shape plots and equivalent stress contour,

- Graphics illustrating kinetic energy and internally consumed energy,

- Graphics illustrating penetration depth and striking ship velocity.

Maximum plastic strains and equivalent stresses for each collision event are summarized in Table 6. Equivalent stresses are evaluated in accordance with the NORSOK code, taking into account the strain rate enhancement formula. Strain rate is determined as 0.2 , a value normally used in ship collision events to determine stress limit. The details of plastic strain, equivalent stress and energy level change for all load cases are shown in Figures 21 to 71 .

\section{FE RESULTS OF SIDE SHELL COLLISION IMPACT ANALYSIS - OPERATIONAL EVENT}

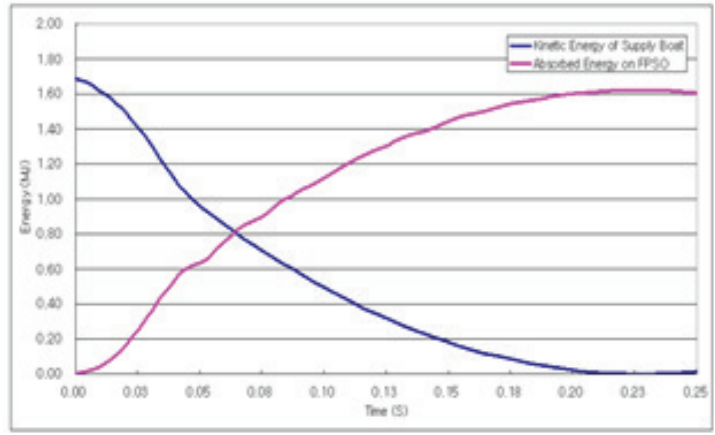

Figure 21.

Time history of kinetic and absorbed energy.

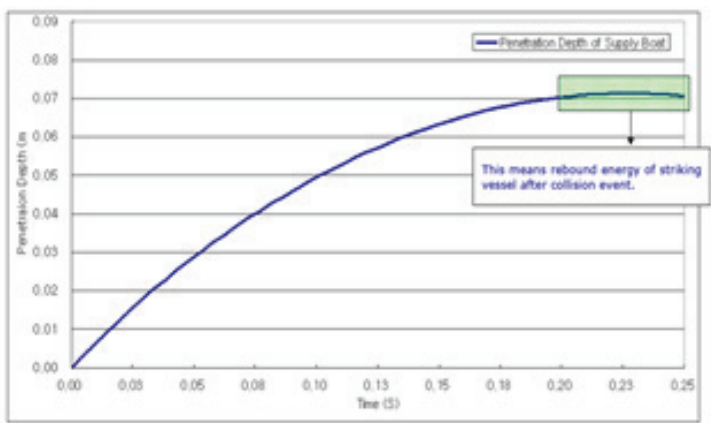

Figure 22.

Time history of supply ship penetration depth.

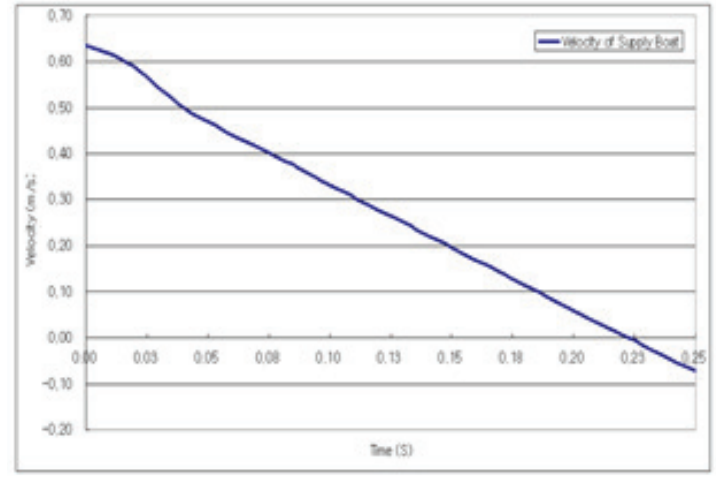

Figure 23

Time history of supply ship velocity.

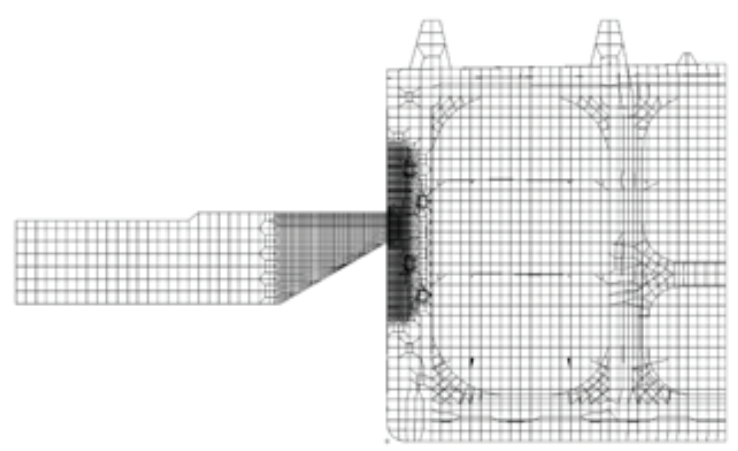

Figure 24

Deformed shape at time $=0.25 \mathrm{sec}$ 


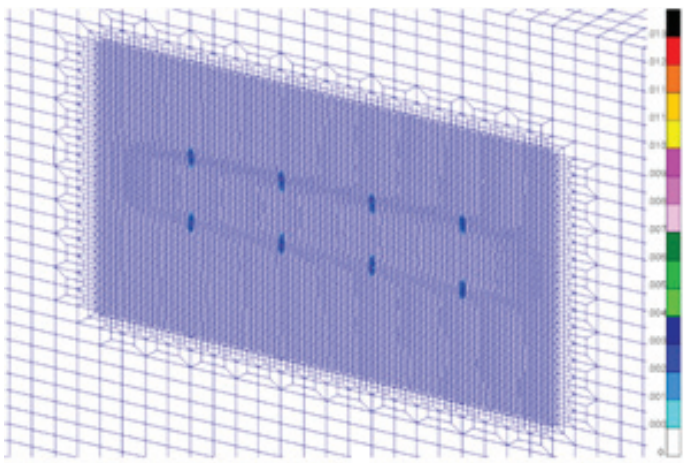

Figure 25.

Deformed shape and plastic strain contour of side shell plating at time $=0.25 \mathrm{sec}$.

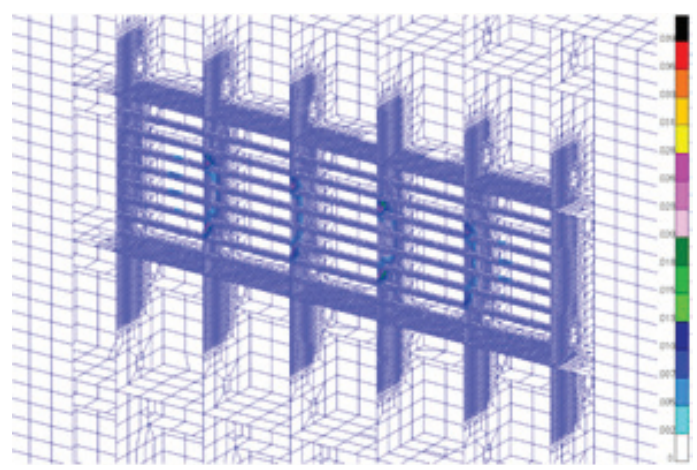

Figure 26.

Deformed shape and plastic strain contour of inner hull structure at time $=0.25 \mathrm{sec}$.

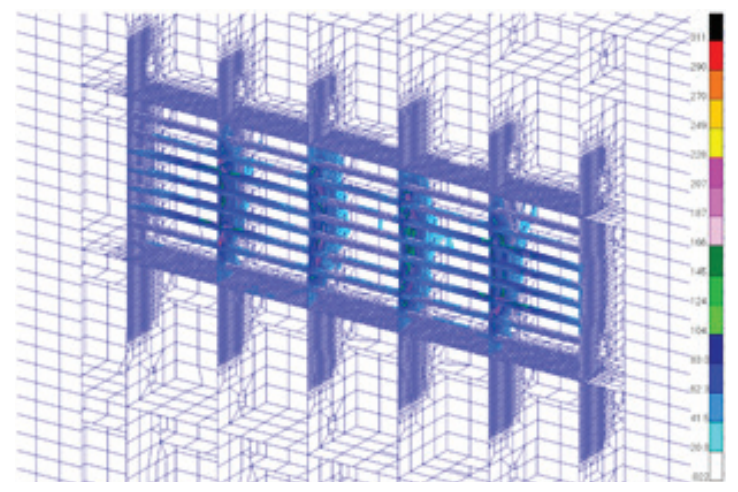

Figure 27.

Deformed shape and equivalent stress contour of inner hull structure at the end of collision.

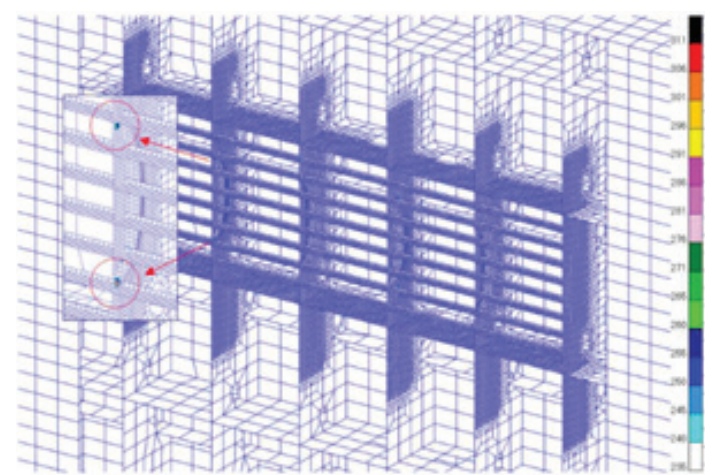

Figure 28.

Deformed shape and equivalent stress contour over yielding.

\section{FE RESULTS OF SIDE SHELL IMPACT ANALYSIS - ACCIDENTAL EVENT}

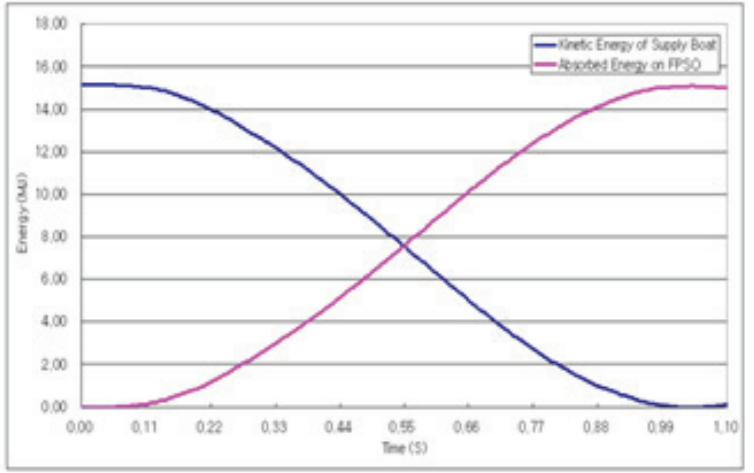

Figure 29.

Time history of kinetic and absorbed energy.

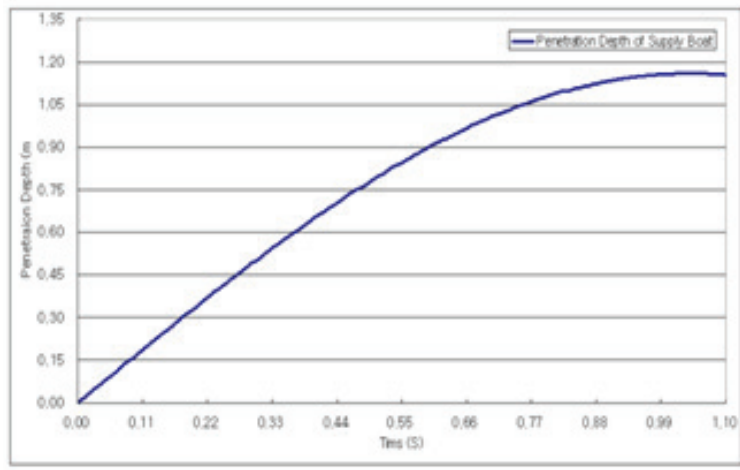

Figure 30.

Time history for supply ship penetration depth. 


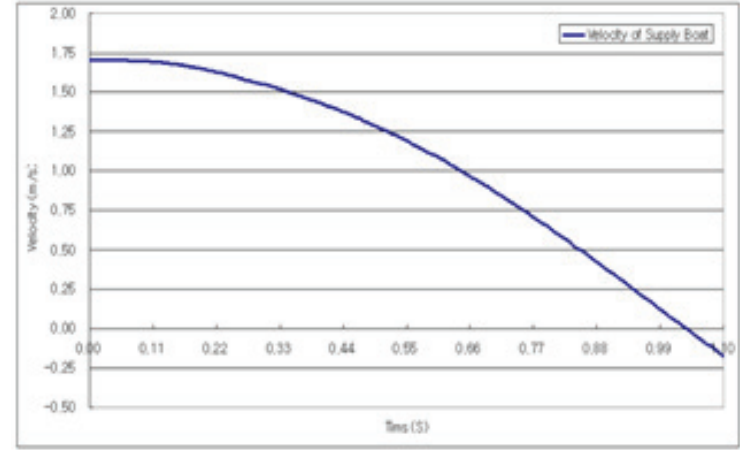

Figure 31.

Time history for supply ship velocity.

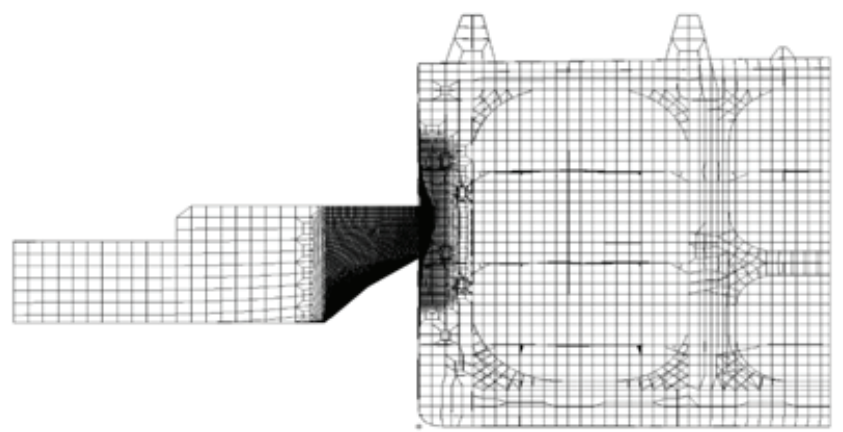

Figure 32.

Deformed shape at time $=1.10 \mathrm{sec}$.

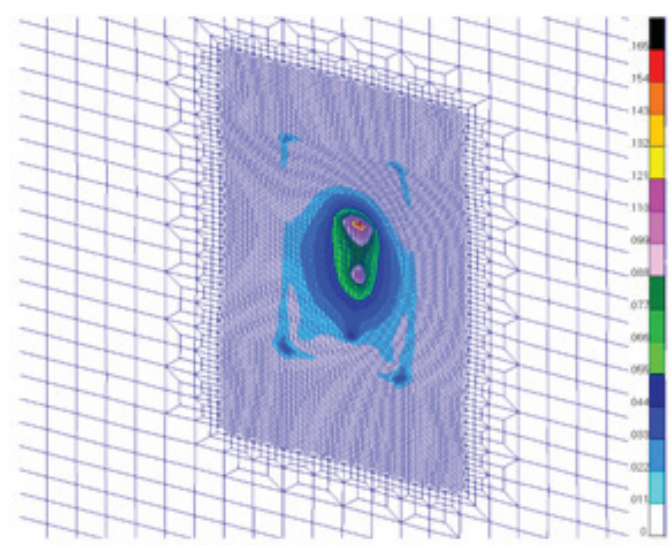

Figure 33.

Deformed shape and plastic strain contour of side shell plating at time $=1.10 \mathrm{sec}$.

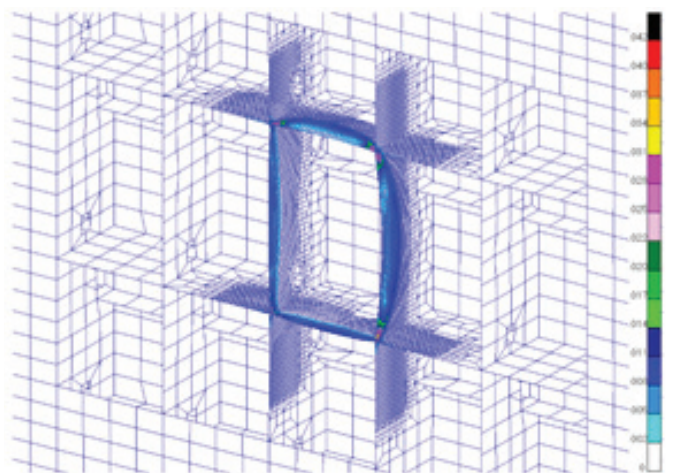

Figure 34.

Deformed shape and plastic strain contour of inner hull structure at time $=1.10 \mathrm{sec}$

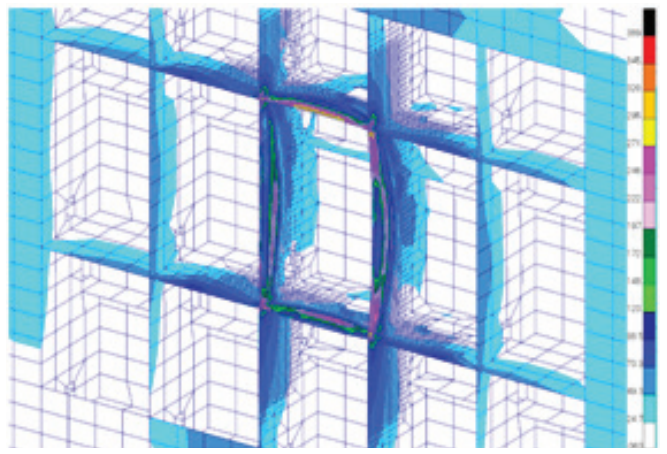

Figure 35.

Deformed shape and equivalent stress contour of inner hull structure at the end of collision.

\section{FE RESULTS OF SIDE SHELL IMPACT ANALYSIS - CRITICAL EVENT}

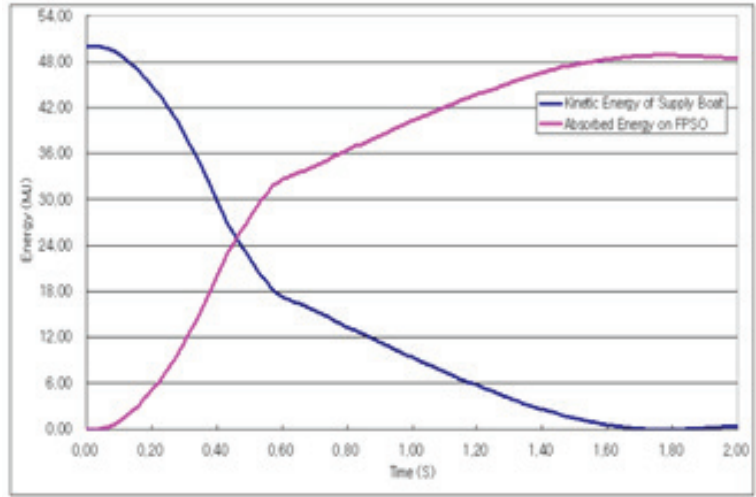

Figure 36

Time history for kinetic and absorbed energy. 


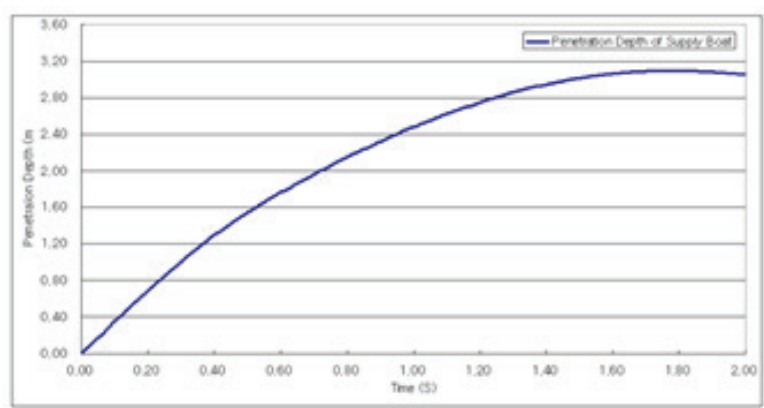

Figure 37.

Time history for supply ship penetration depth.

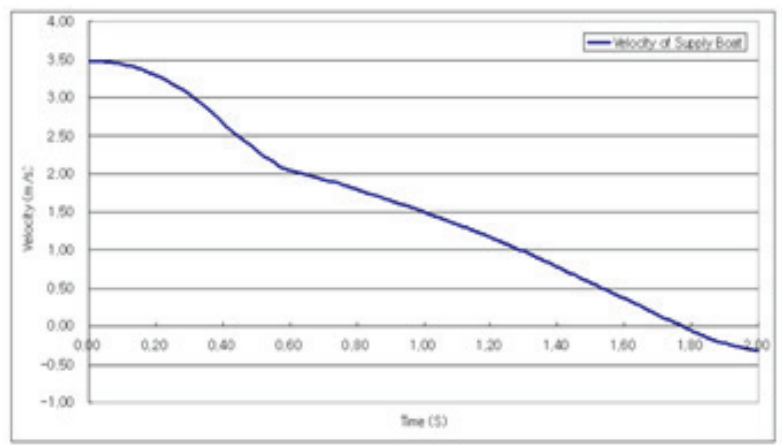

Figure 38.

Time history for supply ship velocity.

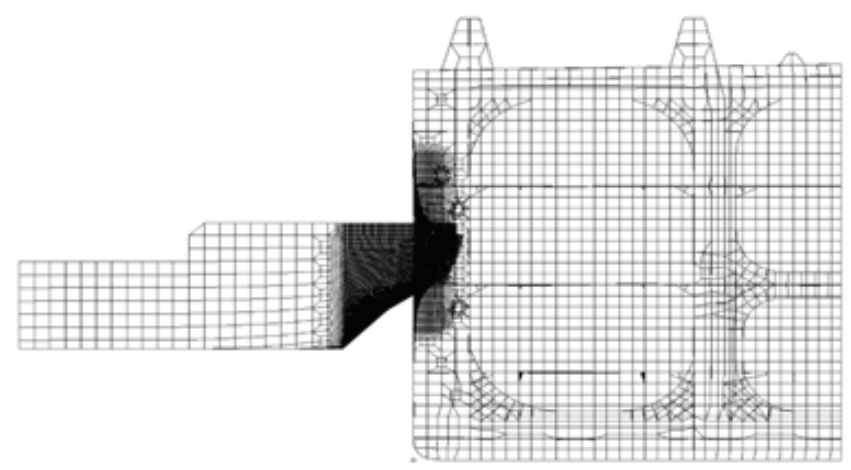

Figure 39.

Deformed shape at time $=2.00 \mathrm{sec}$.

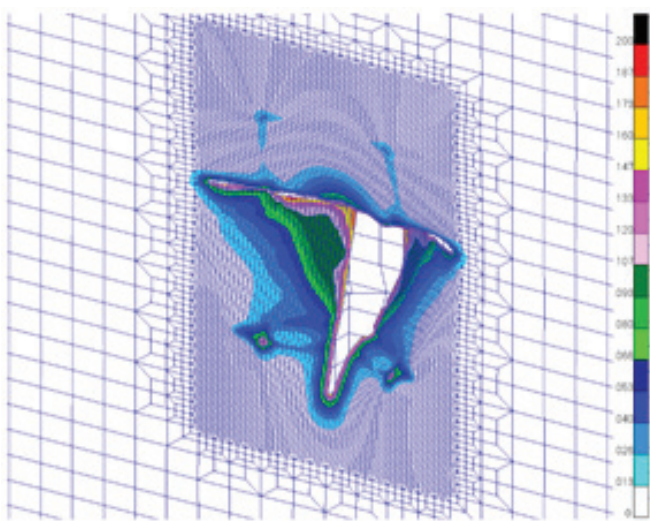

Figure 40.

Deformed shape and plastic strain contour of side shell plating at time $=2.00 \mathrm{sec}$. Deformed shape at time $=2.00$ sec.

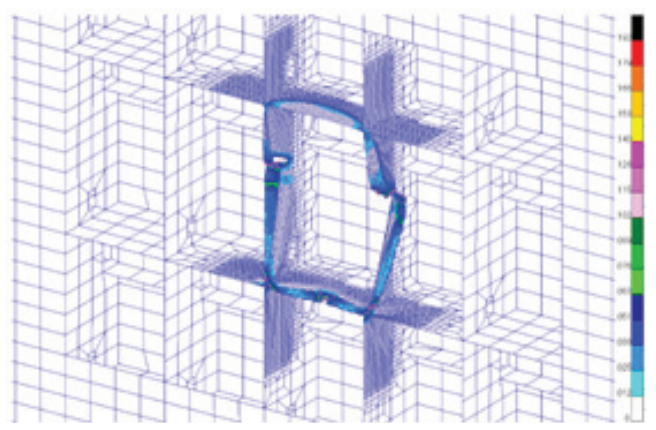

Figure 41.

Deformed shape and plastic strain contour of inner hull structure at time $=2.00 \mathrm{sec}$.

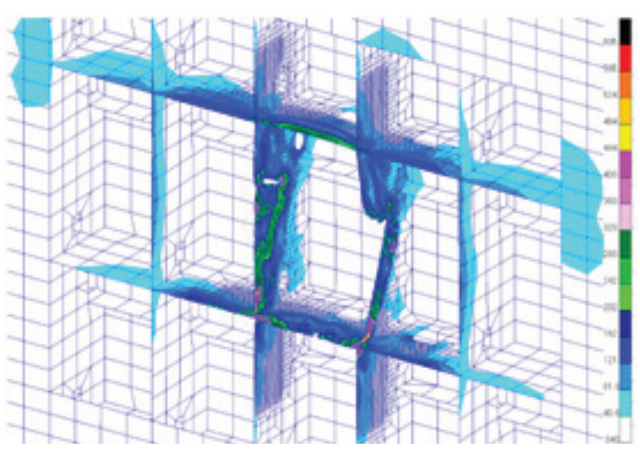

Figure 42.

Deformed shape and equivalent stress contour of inner hull structure at the end of collision. 
15. FE RESULTS OF BOW IMPACT ANALYSIS ACCIDENTAL EVENT

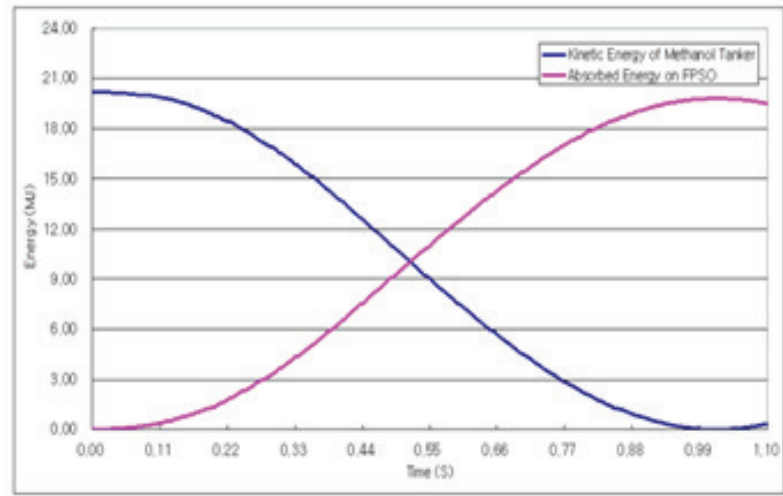

Figure 43.

Time history for kinetic and absorbed energy.

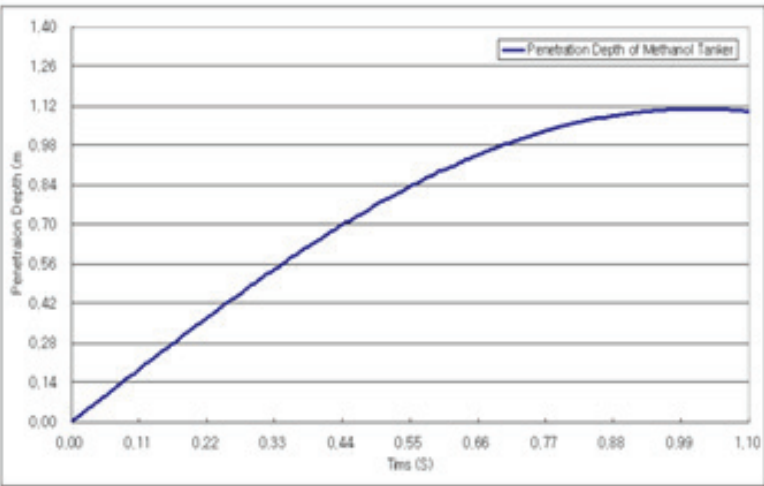

Figure 44

Time history for methanol tanker penetration depth.

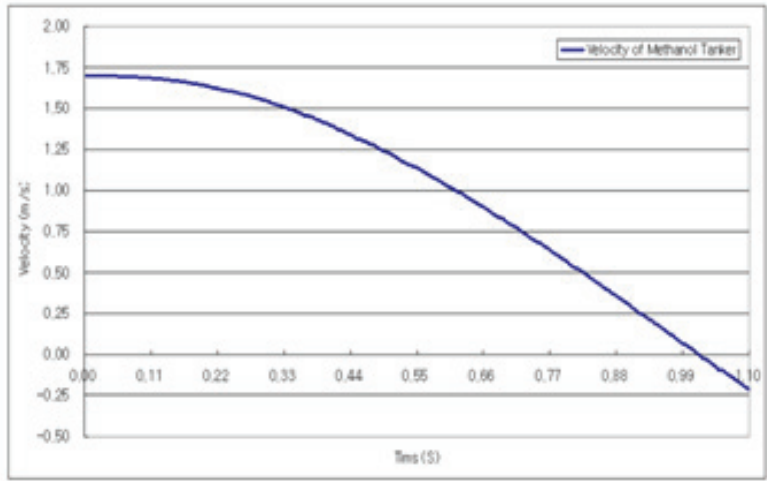

Figure 45.

Time history for methanol tanker velocity.

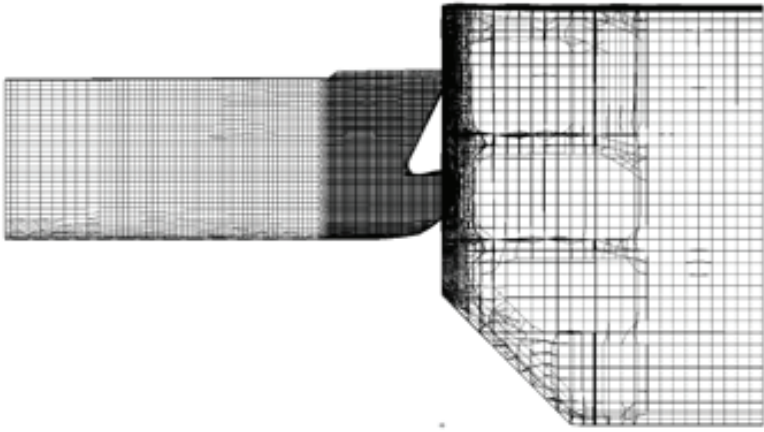

Figure 46

Deformed shape at time $=1.10 \mathrm{sec}$.

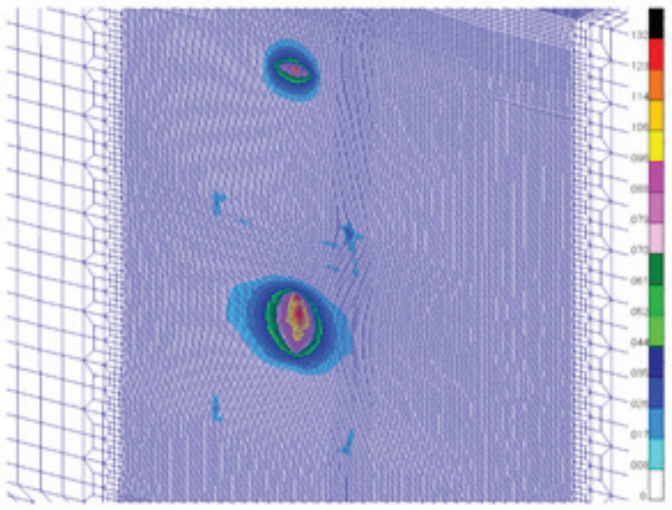

Figure 47.

Deformed shape and plastic strain contour of side shell plating at time $=1.10 \mathrm{sec}$.

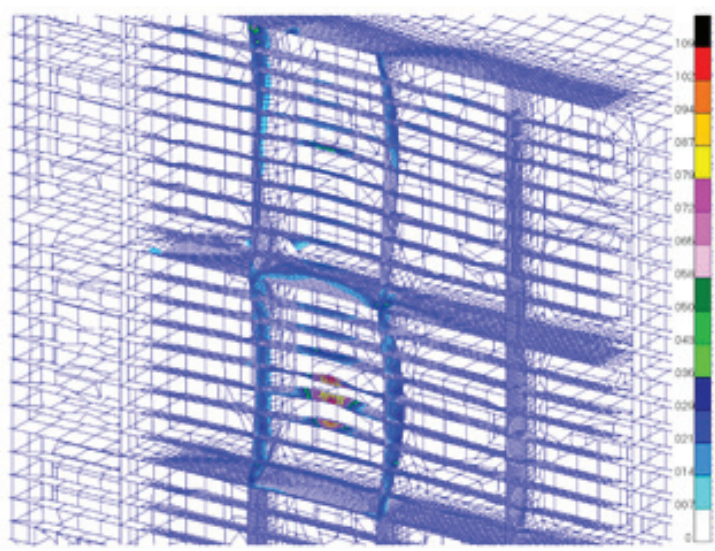

Figure 48.

Deformed shape and plastic strain contour of inner hull structure at time $=1.10 \mathrm{sec}$. 


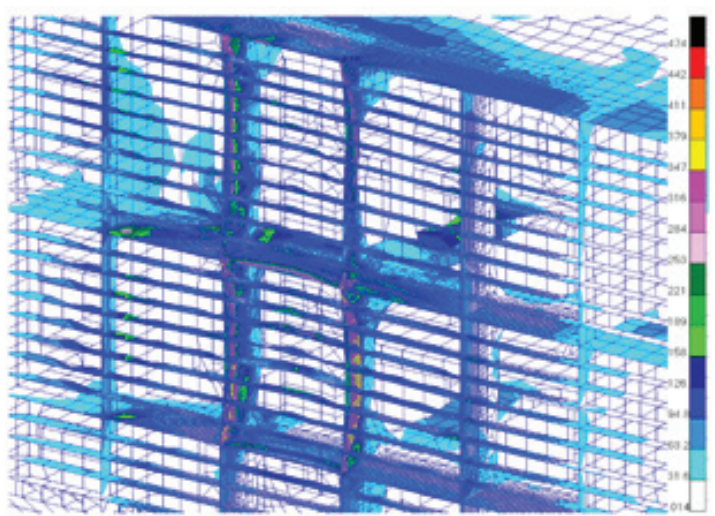

Figure 49.

Deformed shape and equivalent stress contour of inner hull structure at the end of collision.

\section{FE RESULTS OF BOW IMPACT ANALYSIS - CRITICAL EVENT}

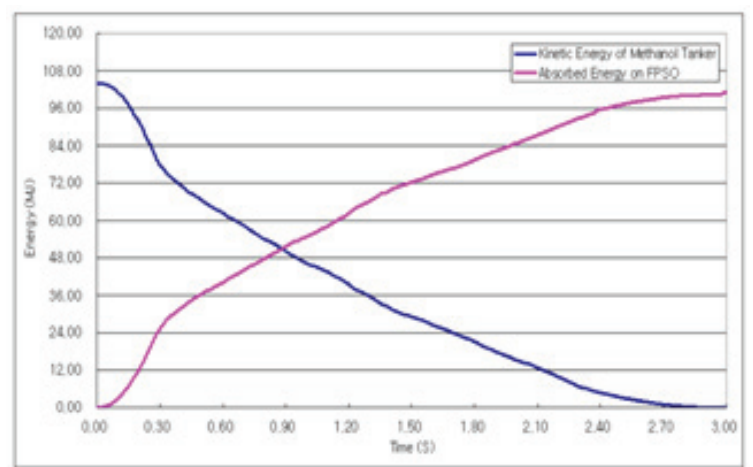

Figure 50.

Time history for kinetic and absorbed energy.

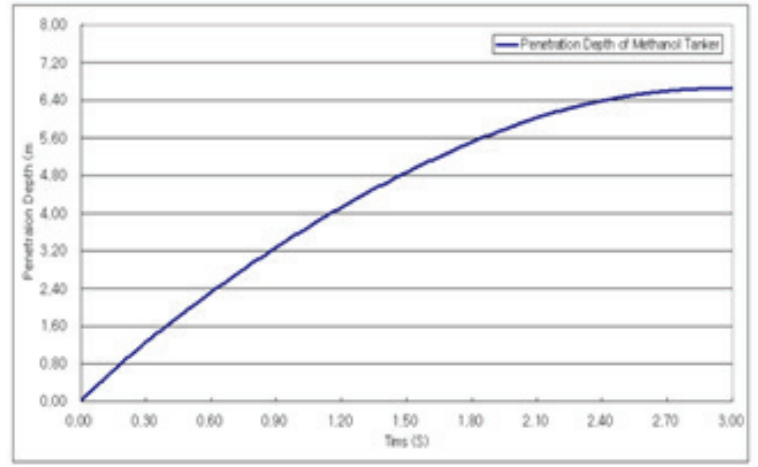

Figure 51.

Time history for methanol tanker penetration depth.

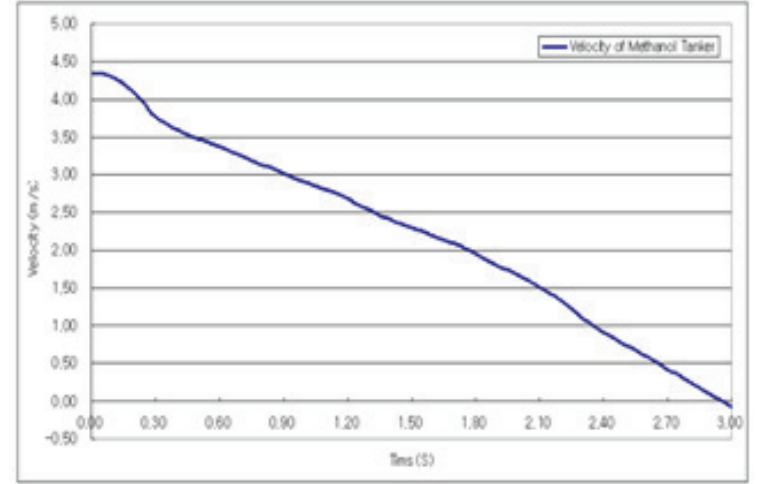

Figure 52.

Time history for methanol tanker velocity.

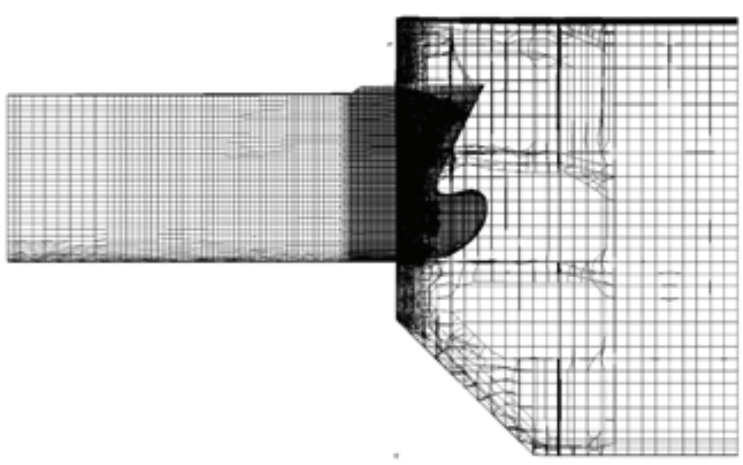

Figure 53.

Deformed shape at time $=3.00 \mathrm{sec}$.

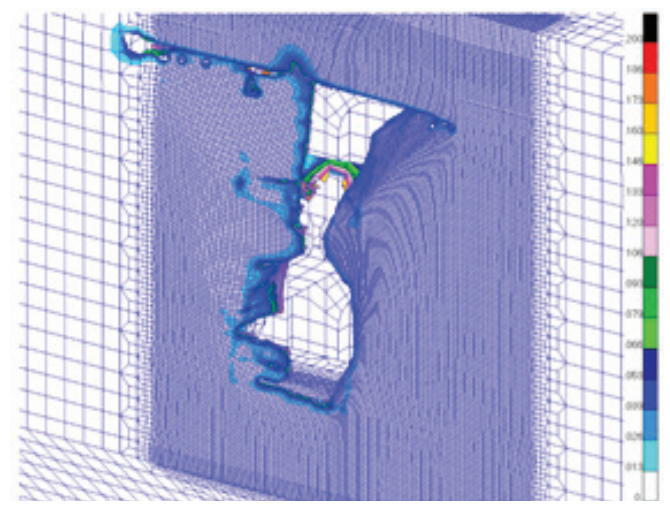

Figure 54.

Deformed shape and plastic strain contour of side shell plating at time $=3.00 \mathrm{sec}$. 


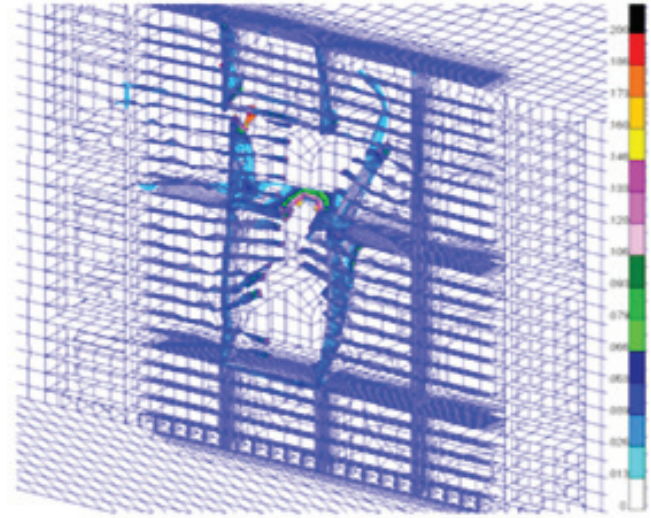

Figure 55.

Deformed shape and plastic strain contour of inner hull structure at time $=3.00 \mathrm{sec}$.

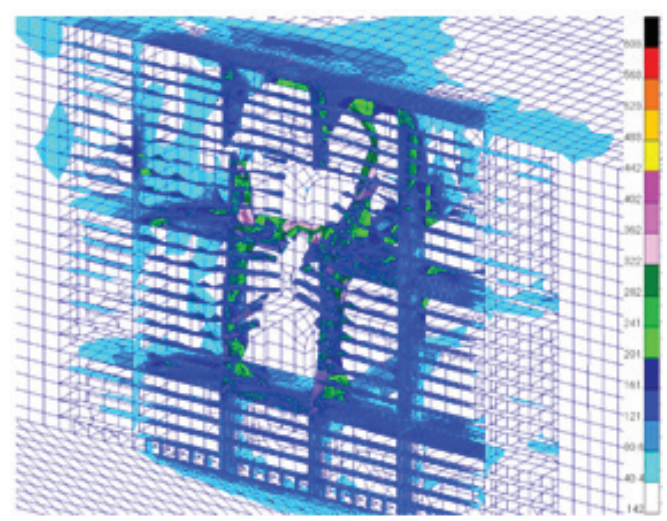

Figure 56.

Deformed shape and equivalent stress contour of inner hull structure at the end of collision.

\section{FE RESULTS FOR STERN IMPACT ANALYSIS - ACCIDENTAL EVENT}

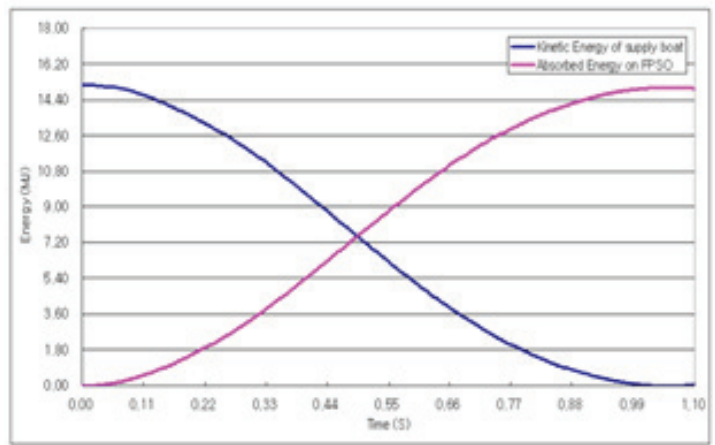

Figure 57.

Time history for kinetic and absorbed energy.

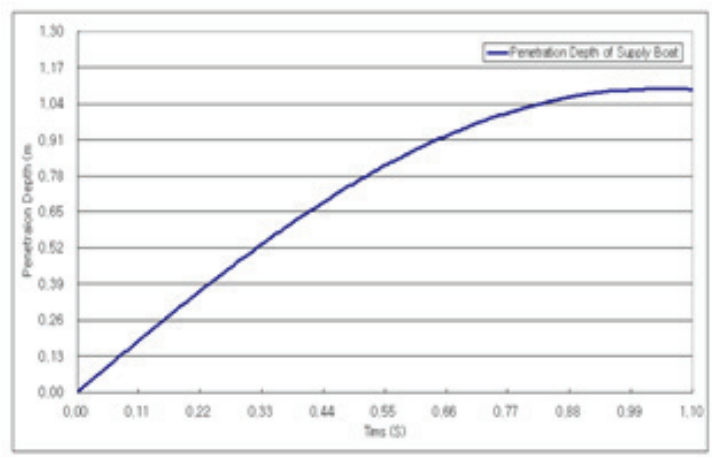

Figure 58

Time history for supply ship penetration depth.

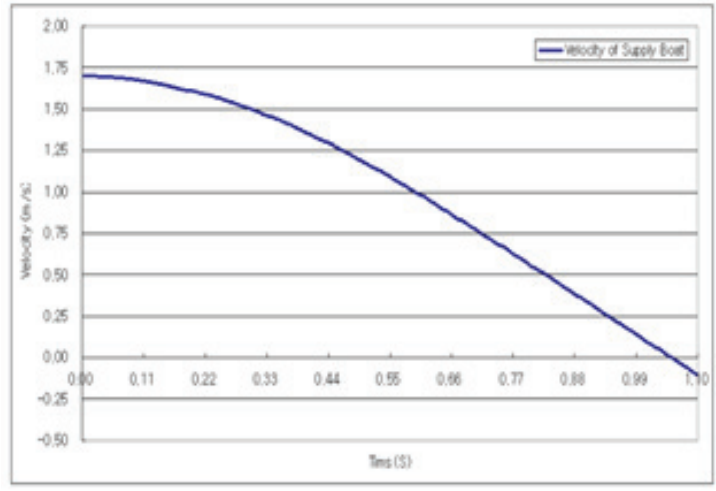

Figure 59.

Time history for supply ship velocity.

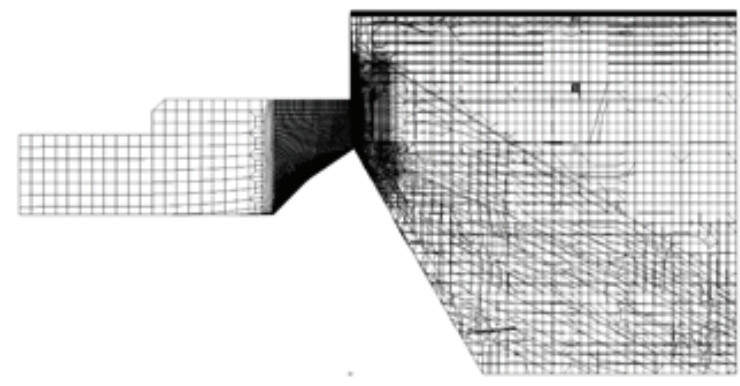

Figure 60

Deformed shape at time $=1.10 \mathrm{sec}$. 


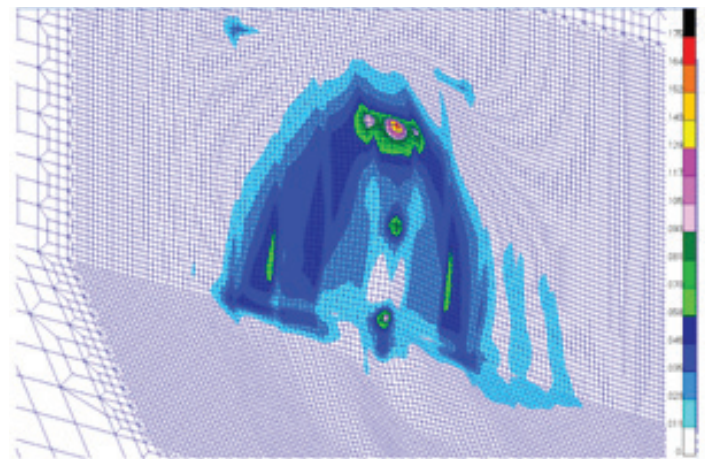

Figure 61.

Deformed shape and plastic strain contour of side shell plating at time $=1.10 \mathrm{sec}$.

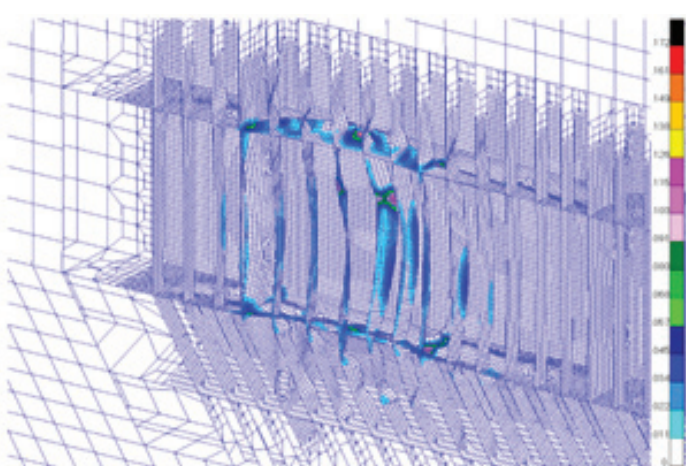

Figure 62.

Deformed shape and plastic strain contour of inner hull structure at time $=1.10 \mathrm{sec}$.

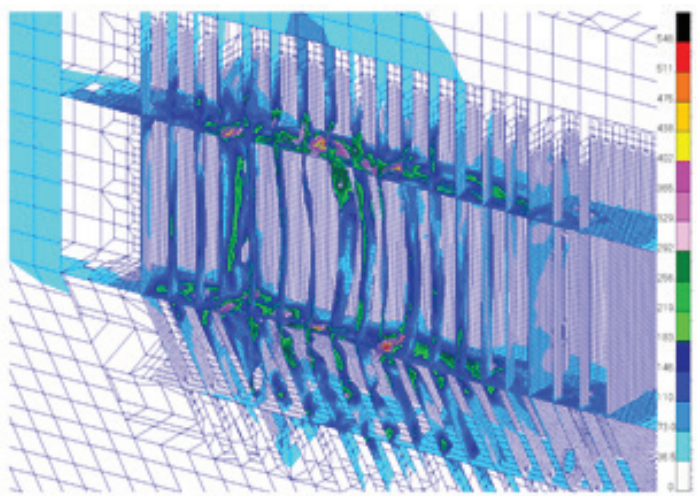

Figure 63.

Deformed shape and equivalent stress contour of inner hull structure at the end of collision.

\section{FE RESULTS FOR STERN IMPACT ANALYSIS - CRITICAL EVENT}

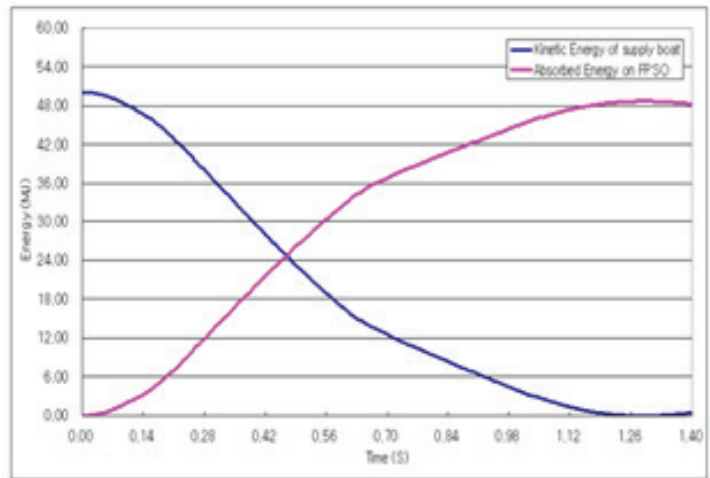

Figure 64.

Time history for kinetic and absorbed energy.

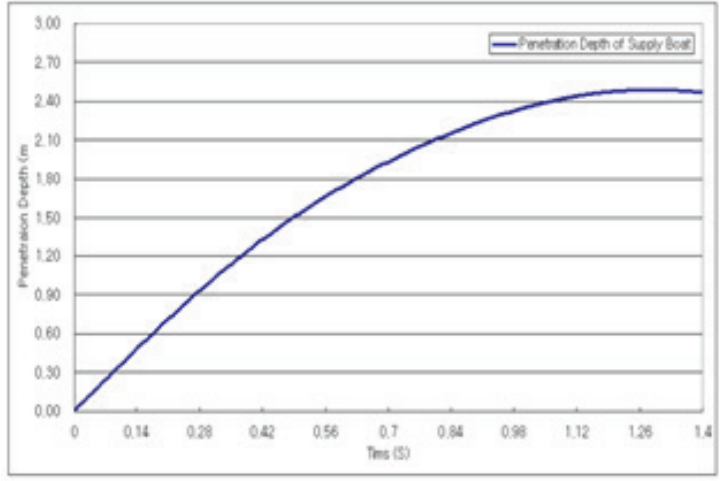

Figure 65.

Time history for supply ship penetration depth.

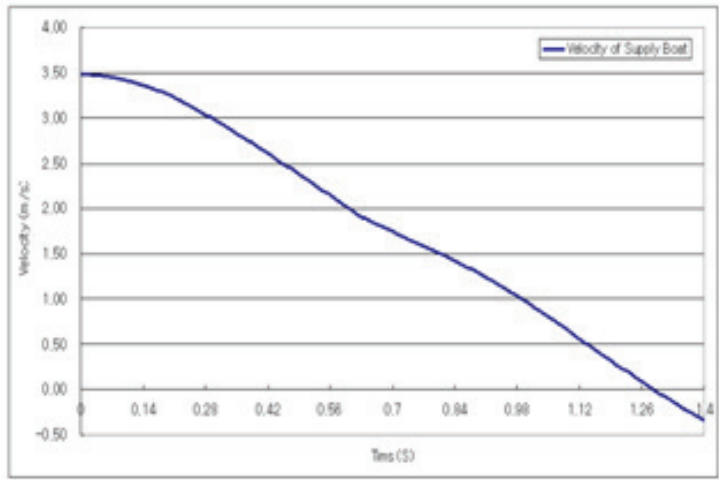

Figure 66.

Time history for supply ship velocity. 


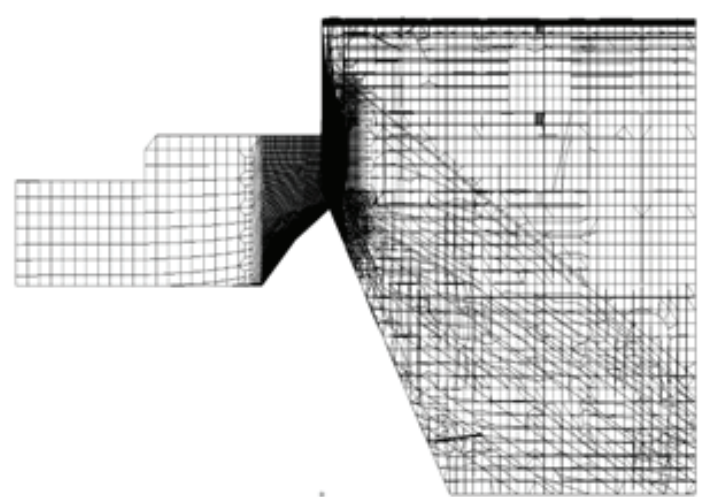

Figure 67.

Deformed shape at time $=1.40 \mathrm{sec}$.

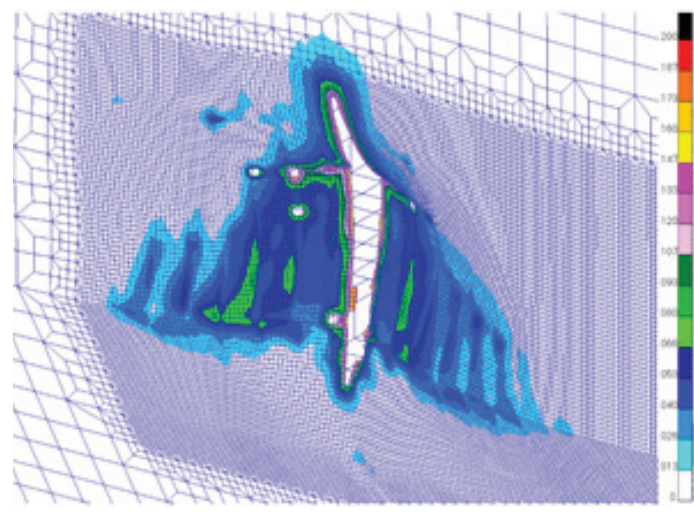

Figure 68.

Deformed shape and plastic strain contour of side shell plating at time $=1.40 \mathrm{sec}$

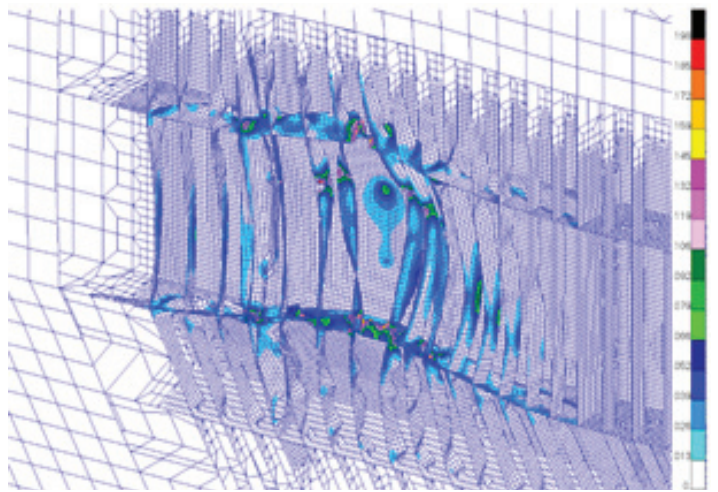

Figure 69.

Deformed shape and plastic strain contour of inner hull structure at time $=1.40 \mathrm{sec}$

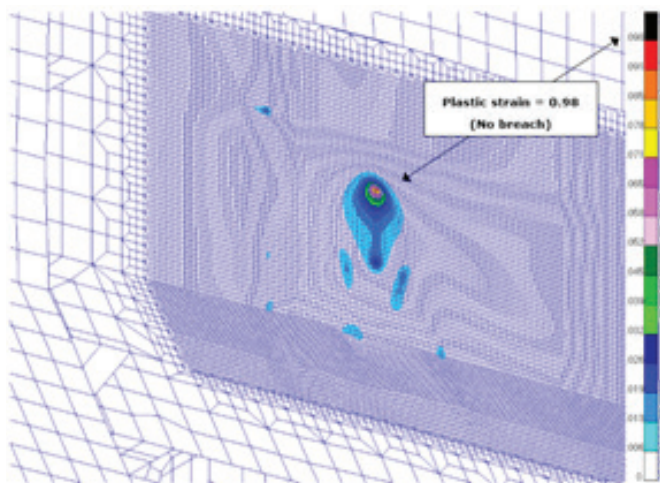

Figure 70.

Deformed shape and plastic strain contour of inner shell at time $=1.40 \mathrm{sec}$

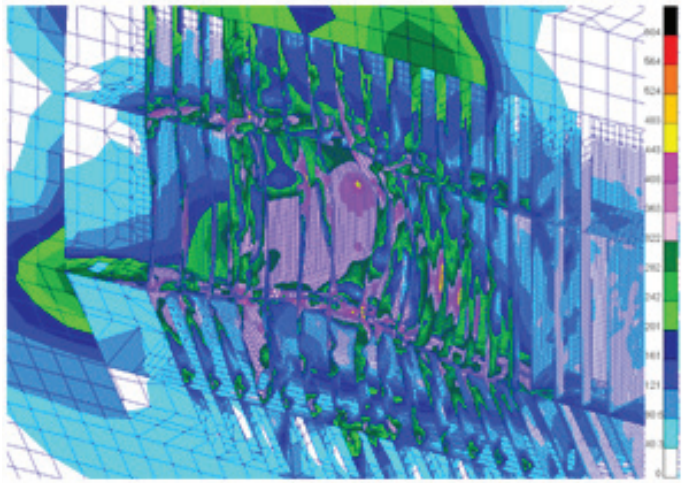

Figure 71.

Deformed shape and equivalent stress contour of inner hull structure at the end of collision.

To ensure that the collision simulations are conducted correctly, both the striking vessel's kinetic energy and the FPSO hull structure's absorbed internal energy were plotted based on the time history. In all cases, kinetic energy started from the required energy level and the internal energy was equal to the initial kinetic energy of the impacting vessel. The results of analyses indicated in Table 6 show that collision loads were correctly distributed and that simulations were reasonably performed. Structural strength was estimated by comparing the maximum stress obtained by collision analysis with the stress limit stipulated in the NORSOK code, taking into account the increase in strain rate. 
Table 6.

Results of collision impact analyses.

\begin{tabular}{|c|c|c|c|c|c|c|c|c|}
\hline \multirow{2}{*}{$\begin{array}{l}\text { Collision } \\
\text { location }\end{array}$} & \multirow{2}{*}{ Loading and energy } & \multirow{2}{*}{$\begin{array}{l}\text { Collison } \\
\text { direction }\end{array}$} & \multirow{2}{*}{ Material } & \multicolumn{2}{|c|}{ Plastic strain (\%) } & \multicolumn{2}{|l|}{ Equiv. stress(MPa) } & \multirow{2}{*}{ Result } \\
\hline & & & & Max. result & Criteria & Max. stress & Stresslimit & \\
\hline \multirow{3}{*}{ Side Shell } & Operational 1.7 MJ & Stern & Mild & 3.9 & 20.0 & 311 & 316 & Satisfactory \\
\hline & Accidental $15.2 \mathrm{MJ}$ & Bow & Mild & 16.5 & 20.0 & 369 & 606 & Satisfactory \\
\hline & Critical $50 \mathrm{MJ}$ & Bow & Mild & Over criteria & 20.0 & Over stress limit & 606 & $\begin{array}{l}\text { No contact } \\
\text { inner hull }\end{array}$ \\
\hline \multirow[b]{2}{*}{ Bow } & Accidental $20.5 \mathrm{MJ}$ & Bow & HT-32 & 13.2 & 16.7 & 474 & 606 & Satisfactory \\
\hline & Critical $104 \mathrm{MJ}$ & Bow & HT-32 & Over criteria & 16.7 & Over stress limit & 606 & $\begin{array}{l}\text { No contact } \\
\text { inner } \\
\text { bulkhead }\end{array}$ \\
\hline \multirow[b]{2}{*}{ Stern } & Accidental 15.2 MJ & Bow & Mild & 17.5 & 20.0 & 548 & 606 & Satisfactory \\
\hline & Critical $50 \mathrm{MJ}$ & Bow & Mild & Over criteria & 20.0 & Over stress limit & 606 & $\begin{array}{l}\text { Contact inner } \\
\text { hull but no } \\
\text { breach }\end{array}$ \\
\hline
\end{tabular}

\section{ACCEPTANCE CRITERIA AND CONSEQUENCE EVALUATION}

Structural damage caused by ship collision accidents can have serious consequences. For example, the reduction of a ship's longitudinal strength may induce global hull collapse. The assessment of global strength after collision damage is thus a necessary step in design. Furthermore, other consequences, such as oil spills, consequent salvage flooding and riser collision consequences have all attracted much attention by the scholars. Global strength has always been a key concern for damaged ships after collision accidents (ISSC 2018).

Obisesan et al. (2016) proposed a framework for reliability assessment of ship hull damage in the event of bow impact. They used reliability computations to show that the probability of hull fracture increases as the hull deformation progresses, with maximum value occurring at the onset of outer hull fracture. Youssef, Faisal et al. (2016) proposed a method for the assessment of risk of ship hull collapse following a collision. They used a probabilistic approach to establish a correlation between the exceedance probability of collision and the residual ultimate longitudinal strength index.

Begovic (2017) carried out an experimental study on hull girder loads on an intact and a damaged naval ship DTMB 5415 at zero speed. He found that moorings influence hull girder loads at some wave frequencies. The global responses of ships suffering impact during collision were investigated by Jia and Moan (2015), with emphasis on hydrodynamic effects. They found that equivalent added mass for sway motion depends not only on the duration of collision impact and impact force, but on collision location as well. Comparatively, the equivalent added mass for yaw motion could be assumed to be independent of collision location. Flooding in damaged ships has also been a matter of concern.

Afenyo et al. (2016) made a state-of the-art review of the fate and transport of oil spills in open and ice-covered water. The review identified the current knowledge gaps and future research directions.

Inadequate longitudinal strength may cause an FPSO to collapse after collision. The residual strength of damaged structures must be maintained at a certain level to avoid additional catastrophic consequences. A measure of residual bending capacity can be based on either the maximum elastic bending moment corresponding to occurrence of initial yielding (section modulus-based residual strength), or the maximum bending moment beyond which the ship will break its back due to extensive yielding and buckling (ultimate bending momentbased residual strength). Figure 72 presents the vertical extent of the damaged members in a critical collision event, which is the most dangerous scenario strength-wise. Figure 73 illustrates the moment of inertia of an intact structure, while Figure 74 shows the moment of inertia of a damaged structure in a critical collision event.

Ultimate hull girder bending capacity was calculated for undamaged and damaged mid-ship sections shown in Table 7 and Table 8. According to calculation, inertia moment reduction due to loss of side structural members is less than $1 \%$. 
Table 7.

Hull girder strength criteria for undamaged (intact).

\begin{tabular}{ll} 
Modulus at deck $\left(\mathrm{m}^{3}\right)$ & 120.11 \\
\hline Modulus at bottom $\left(\mathrm{m}^{3}\right)$ & 118.55 \\
\hline Inertia $\left(\mathrm{m}^{4}\right)$ & 1909.11 \\
\hline
\end{tabular}

Table 8.

Hull girder strength criteria for damaged section.

\begin{tabular}{ll} 
Modulus at deck $\left(\mathrm{m}^{3}\right)$ & 119.88 \\
\hline Modulus at bottom $\left(\mathrm{m}^{3}\right)$ & 118.22 \\
\hline Inertia $\left(\mathrm{m}^{4}\right)$ & 1904.65 \\
\hline
\end{tabular}

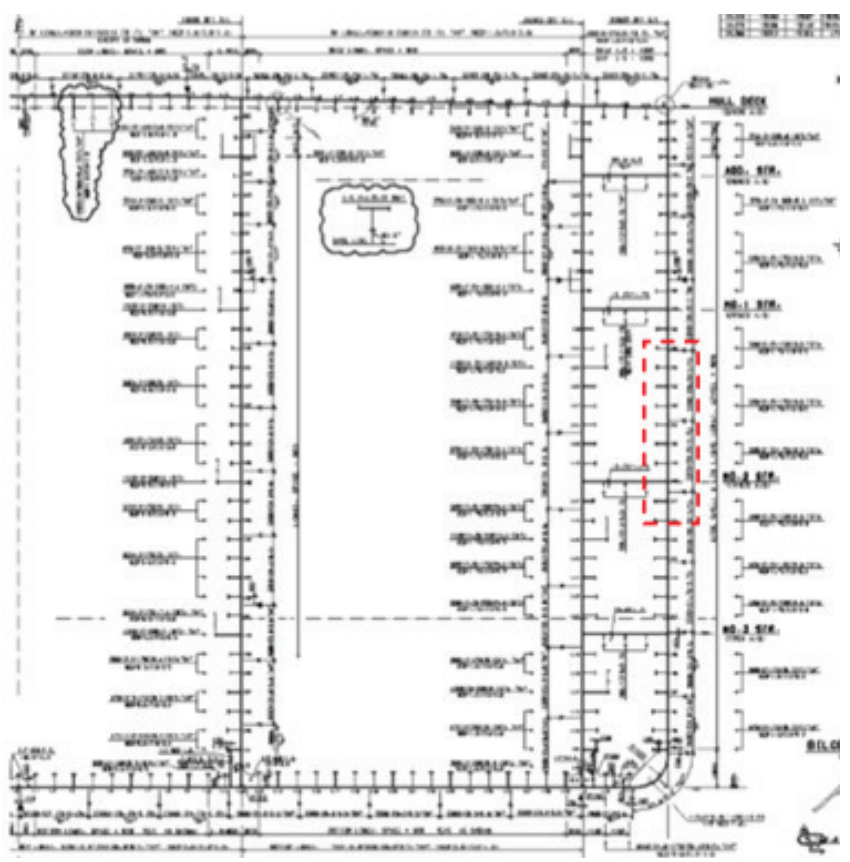

Figure 72.

Vertical extent of the damaged members in a critical collision event (the most dangerous case).

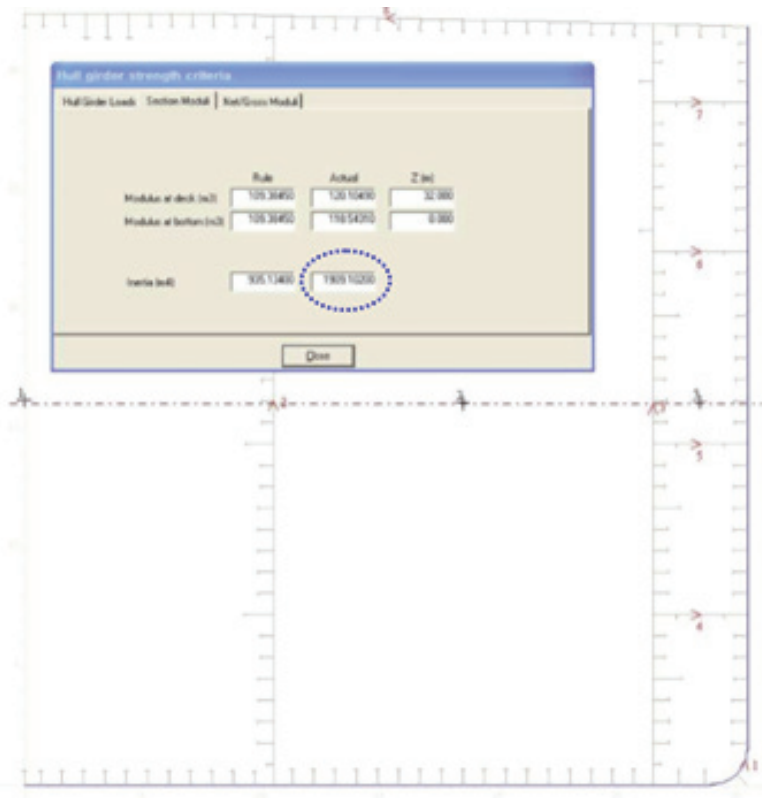

Figure 73.

Moment of inertia of intact structure.

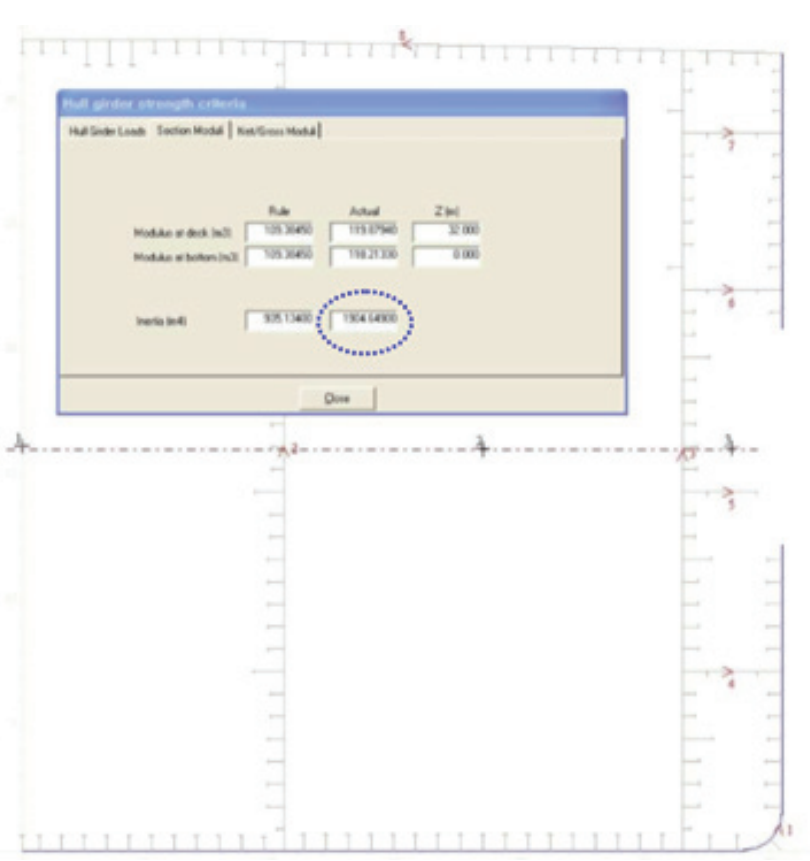

Figure 74.

Moment of inertia of damaged structure in a critical collision event. 


\section{CONCLUSION}

Offshore platforms operating at sea are at risk of impacts with ships. Potential impacts can range from minor local structural deformations to significant threats to structural integrity, resulting in major economic losses, serious environmental contamination, and fatalities. Accidental loads can, under severe circumstances, result in the global collapse of whole structures and put people's lives at risk.

Collision impact analyses based on numerical impact simulations were conducted to examine the protection of FPSO vessel's hull during collision accidents with striking ships. In the side shell structure operational scenario, the impact analysis of collision indicates that certain elements surpass yield stress, but the damage is minor. In this case, as impact energy is primarily absorbed by elastic deformation of hull structure, slight plastic deformation occurred. Damage sustained by hull plating in this type of collision event was minor.

Rupture strain percentage by steel grade, the extent of hull damage in different collision scenarios and impact energy levels are determined using the guidelines contained in the NORSOK code "Design of steel structure N-004".

In all accidental collisions kinetic energy was absorbed by plastic deformation and there were no failures. Though hull structure sustained significant plastic deformations, there were no leakages.

In the event of a critical collision, for verification purposes only, the intactness of inner hull structure at impact locations in case of breach of the outer shell structure was checked. Several elements of the hull structure exceeded the fracture strain for vital collision of side shell and bow structures, but the striking ship did not strike the inner hull collision bulkhead. Supply ship collided with the inner hull in critical collisions with stern structures, but without breaching the internal hull plating.

Flare tower should be positioned so as to minimise the risk of ignition of a gas-cloud coming from the process installation. If an over water cantilevered solution is considered, it should be positioned at a height sufficient to avoid collision with passing vessels, including export tankers.

The offloading and mooring points should be positioned so as to minimise the risk of collision with export tanker or risk of offloading hose rupture. Their position needs to be checked under various environmental conditions and in different FPSO's positions.

Location of risers is determined with consideration of the risk of damage due to events such as collision by external vessels (including export tanker).

Supply ship operations must therefore be carried out carefully at the stern part of the FPSO. In accordance with the acceptance criteria, the FPSO hull structure was confirmed to have adequate structural strength to meet the design criteria for collision occurrences. Furthermore, an ultimate hull girder bending capacity was tested for intact and damaged conditions at mid-ship sections. According to simulations, inertia moment reduction due to loss of side structural members was less than $1 \%$.

Due to the short duration of events, collision analyses are usually conducted using explicit solvers in which the kinetic energy of a dropped object is converted to strain energy of the struck and the striking body. Material failure is also considered in studies in which implicit element formulations are inadequate. Special attention should be paid to enforced boundary conditions; fixed conditions of the struck body often applied at a distance away from the striking point are typical. The striking body can be modelled wholly or partially. In the latter case, the initial velocity of the entire body should be used.

The usual output of concern is force deflection, i.e. energy dissipation-deflection curve. The greatest attention should be paid to the establishment of credible failure criteria and creating mesh size based on recommended practices where applicable. Most commercial codes nowadays support a series of failure criteria that remove elements as soon as certain limits are exceeded. Typical failure criteria are based on geometric strain, plastic strain, element distortion or time step.

Finally, the findings of the present study will improve our understanding of the collision response of offshore platforms and evaluation procedures and provide efficient guidance for the design and operation of FPSOs.

\section{REFERENCES}

Afenyo, M., Veitch, B. \& Khan, F., 2016. A state-of-the-art review of fate and transport of oil spills in open and ice-covered water. Ocean Engineering, 119, pp.233-248. Available at:

http://dx.doi.org/10.1016/j.oceaneng.2015.10.014.

Amante, D. do A.M. \& Estefen, S.F., 2018. Collisions Between Ships and Platforms in Brazilian Waters. Volume 3: Structures, Safety, and Reliability. Available at: http://dx.doi.org/10.1115/omae2018-78199.

Amdahl, J. et al., 2012. Broad Side Ship Collision With Jacket Legs: Examination of NORSOK N-004 Analysis Procedure. Volume 2: Structures, Safety and Reliability. Available at:

http://dx.doi.org/10.1115/omae2012-84266.

Begovic, E., Day, A.H. \& Incecik, A., 2017. An experimental study of hull girder loads on an intact and damaged naval ship. Ocean Engineering, 133, pp.47-65. Available at: http://dx.doi.org/10.1016/j.oceaneng.2017.02.001.

Brown, A.J., 2002. Collision scenarios and probabilistic collision damage. Marine Structures, 15(4-5), pp.335-364. Available at:

http://dx.doi.org/10.1016/s0951-8339(02)00007-2. 
Calle, M.A.G., Oshiro, R.E. \& Alves, M., 2017. Ship collision and grounding: Scaled experiments and numerical analysis. International Journal of Impact Engineering, 103, pp.195-210. Available at:

http://dx.doi.org/10.1016/j.jijimpeng.2017.01.021.

Det Norske Veritas Offshore Standard, 2019. DNVGL-OS-C102. Høvik, Norway.

DNVGL-RP-C204, 2010. Design against Accidental Loads, Det Norske Veritas, Høvik, Norway.

DNVGL-RP-C208, 2019. Determination of Structural Capacity by Non-linear FE Analysis Methods, Recommended Practice, Det Norske Veritas, Høvik, Norway.

Health and Safety Executive (HSE), 2000. Collision resistance of ship-based structures to side impact, OTO 053/2000.

ISSC 2018, Proceedings of the 20th International Ship and Offshore Structures Congress (ISSC 2018) Volume II - M.L. Kaminski and P. Rigo (Eds.), Committee V.1 Accidental Limit States.

ISSC, 2003. Committee V.3 Collision and Grounding. The 15th International Ship and Offshore Structures Congress (ISSC), San Diego, USA.

ISSC, 2006. V.1. Collision and Grounding. The 16th Int. Ship and Offshore Structures Congress 2, Southampton, UK.

Jia, H. \& Moan, T., 2015. Global Responses of Struck Ships in Collision With Emphasis on Hydrodynamic Effects. Journal of Offshore Mechanics and Arctic Engineering, 137(4). Available at:

http://dx.doi.org/10.1115/1.4030343.

Liu, B., Villavicencio, R. \& Guedes Soares, C., 2015a. Simplified method for quasistatic collision assessment of a damaged tanker side panel. Marine Structures, 40, pp.267-288. Available at: http://dx.doi.org/10.1016/j.marstruc.2014.11.006.

Liu, B., Villavicencio, R. \& Guedes Soares, C., 2015b. Simplified analytical method to evaluate tanker side panels during minor collision incidents. International Journal of Impact Engineering, 78, pp.20-33. Available at: http://dx.doi.org/10.1016/j.ijimpeng.2014.11.021.

LR, 2014. Guidance notes for collision analysis. Lloyd's Register of Shipping.

Moan, T., 2019. Integrity Management of Offshore Structures With Emphasis on Design for Structural Damage Tolerance. Journal of Offshore Mechanics and Arctic Engineering, 142(3). Available at: http://dx.doi.org/10.1115/1.4045373.

Moan, T., Amdahl, J., Wang, X.Z. \& Spencer, J., 2003. Risk Assessment of FPSOs with Emphasis on Collision, SNAME Transactions, 110, pp. 307-339.

Mujeeb-Ahmed, M.P., Seo, J.K. \& Paik, J.K., 2018. Probabilistic approach for collision risk analysis of powered vessel with offshore platforms. Ocean Engineering, 151, pp.206-221. Available at:

http://dx.doi.org/10.1016/j.oceaneng.2018.01.008.

Ning, X., Zhang, B.L. \& Tallavajhula, S., 2013. Structural Integrity of a Spar in Collision With a Large Supply Vessel. Volume 2A: Structures, Safety and Reliability. Available at: http://dx.doi.org/10.1115/omae2013-10213.

NORSOK Standard, 2004a. Design of steel structure N-004, Rev.2 October 2004.

NORSOK Standard, 2004b. Materials selections M-001, Rev.4 August 2004.

NORSOK-N-003, 2017. Action and Action Effects. Edition 3. Standard Norway.
Obisesan, A., Sriramula, S. \& Harrigan, J., 2015. A framework for reliability assessment of ship hull damage under ship bow impact. Ships and Offshore Structures, 11(7), pp.700-719. Available at:

http://dx.doi.org/10.1080/17445302.2015.1051281.

Ozguc, O., 2017. Structural damage of ship-FPSO collisions. Journal of Marine Engineering \& Technology, 18(1), pp.1-35. Available at:

http://dx.doi.org/10.1080/20464177.2017.1359387.

Ozguc, O., 2018. Consideration of Collision Damage in FPSO Structural Design. Journal of Offshore Structure and Technology, 5(2), pp. 1-21.

Ozguc, O., Das, P.K. \& Barltrop, N., 2005. A comparative study on the structural integrity of single and double side skin bulk carriers under collision damage. Marine Structures, 18(7-8), pp.511-547. Available at:

http://dx.doi.org/10.1016/j.marstruc.2006.01.004.

Pedersen, P., 2014. Risk assessment for ship collisions against offshore structures. Maritime Technology and Engineering, pp.11-21. Available at: http://dx.doi.org/10.1201/b17494-4.

Rigueiro, C., Ribeiro, J. \& Santiago, A., 2017. Numerical assessment of the behaviour of a fixed offshore platform subjected to ship collision. Procedia Engineering, 199, pp.2494-2499. Available at:

http://dx.doi.org/10.1016/j.proeng.2017.09.415.

Storheim, M. \& Amdahl, J., 2015. On the sensitivity to work hardening and strain-rate effects in nonlinear FEM analysis of ship collisions. Ships and Offshore Structures, 12(1), pp.100-115. Available at: http://dx.doi.org/10.1080/17445302.2015.1115181.

Szlapczynski, R. \& Szlapczynska, J., 2016. An analysis of domain-based ship collision risk parameters. Ocean Engineering, 126, pp.47-56. Available at: http://dx.doi.org/10.1016/j.oceaneng.2016.08.030.

Tabri, K. \& Broekhuijsen, J., 2011. Influence of ship motions in the numerical prediction of ship collision damage. Advances in Marine Structures, pp.391-397. Available at: http://dx.doi.org/10.1201/b10771-48.

Terndrup Pedersen, P. \& Zhang, S., 1998. On Impact mechanics in ship collisions. Marine Structures, 11(10), pp.429-449. Available at: http://dx.doi.org/10.1016/s0951-8339(99)00002-7.

The 20th International Ship and Offshore Structures Congress, 2018. COMMITTEE V.1 Accidental Limit States, Proceedings of the 20th International Ship and Offshore Structures Congress (ISSC 2018) Volume II.

Travanca, J. \& Hao, H., 2015. Energy dissipation in high-energy ship-offshore jacket platform collisions. Marine Structures, 40, pp.1-37. Available at: http://dx.doi.org/10.1016/j.marstruc.2014.10.008.

Vinnem, J.E., Utne, I.B. \& Schjølberg, I., 2015. On the need for online decision support in FPSO-shuttle tanker collision risk reduction. Ocean Engineering, 101, pp.109117. Available at: http://dx.doi.org/10.1016/j.oceaneng.2015.04.008.

Wang, G. \& Pedersen, P.T., 2007. A Literature Review of Risk Assessment of ShipFPSO Collisions. Volume 2: Structures, Safety and Reliability; Petroleum Technology Symposium. Available at: http://dx.doi.org/10.1115/omae2007-29760.

You, Y. \& Rhee, K., 2016. Development of the collision ratio to infer the time at which to begin a collision avoidance of a ship. Applied Ocean Research, 60, pp.164-175. Available at:

http://dx.doi.org/10.1016/j.apor.2016.09.005. 
Youssef, S.A.M. et al., 2015. Assessing the risk of ship hull collapse due to collision. Ships and Offshore Structures, 11(4), pp.335-350. Available at: http://dx.doi.org/10.1080/17445302.2014.993110.

Yu, Z. \& Amdahl, J., 2016a. Full six degrees of freedom coupled dynamic simulation of ship collision and grounding accidents. Marine Structures, 47, pp.1-22. Available at: http://dx.doi.org/10.1016/j.marstruc.2016.03.001.

Yu, Z. \& Amdahl, J., 2016b. Influence of 6 DOF ship motions in the damage prediction of ship collision and grounding accidents, 7th International Conference on Collision and Grounding of Ships and Offshore Structures, Ships and Offshore Structures, pp. 199-205.

Yu, Z. \& Amdahl, J., 2018. A review of structural responses and design of offshore tubular structures subjected to ship impacts. Ocean Engineering, 154, pp.177-203. Available at:

http://dx.doi.org/10.1016/j.oceaneng.2018.02.009.

Zhang, D., Hu, Z. \& Chen, G., 2015. Research on the Crashworthiness of FLNG Side Structures in the Side-by-Side Offloading Operation With LNGC. Volume 3:
Structures, Safety and Reliability. Available at: http://dx.doi.org/10.1115/omae2015-41363.

Zhang, J. et al., 2015. A distributed anti-collision decision support formulation in multi-ship encounter situations under COLREGs. Ocean Engineering, 105, pp.336348. Available at:

http://dx.doi.org/10.1016/j.oceaneng.2015.06.054.

Zhang, S. et al., 2017. Impact mechanics of ship collisions and validations with experimental results. Marine Structures, 52, pp.69-81. Available at: http://dx.doi.org/10.1016/j.marstruc.2016.12.003.

Zhang, S., Pedersen, P.T. \& Ocakli, H., 2015. Collisions damage assessment of ships and jack-up rigs. Ships and Offshore Structures, pp.1-9. Available at: http://dx.doi.org/10.1080/17445302.2014.1003173.

Zhang, W. et al., 2015. A method for detecting possible near miss ship collisions from AIS data. Ocean Engineering, 107, pp.60-69. Available at:

http://dx.doi.org/10.1016/j.oceaneng.2015.07.046. 